\title{
CONSUMPTION AND INVESTMENT IN RESOURCE POOLING FAMILY NETWORKS*
}

\author{
MANUELA ANGELUCCI, GIACOMO DE GIORGI, IMRAN RASUL ${ }^{\dagger}$
}

SEPTEMBER 2016

\begin{abstract}
This paper examines a novel motive for resource pooling in family networks in rural economies: to relax credit constraints and facilitate investment in non-collateralizeable assets for which credit market imperfections are most binding. We thus complement established literatures examining risk-sharing motives for resource transfers within family networks, as well as motives based on kinship tax obligations. We do so exploiting the Progresa program data, in which family networks can be identified, households are subject to large exogenous resource inflows, and detailed responses on consumption and an array of investments can be tracked in a household panel over five years. We find that for every dollar that accrues to the family network through Progresa transfers, food consumption expenditures increase by around $65 \phi$ for both households eligible for Progresa and ineligible members of the same family network. Hence the marginal propensity of families to invest/save out of every dollar is around .35, and we document how this is channelled towards easing credit constraints poorer network members face in financing non-collateralizable investments into their children's human capital. We show these consumption and investment benefits of being embedded within a family network are sustained five years after households first experience resource transfers from Progresa. Hence the interplay between resource inflows and resource pooling by family networks can place network members on sustained paths out of poverty.
\end{abstract}

JEL Classifications: D12, O1, O12.

\footnotetext{
*Earlier versions of this paper were circulated under the title, "Resource Pooling Within Family Networks: Insurance and Investment". The paper has been screened to ensure no confidential information is revealed and has been conducted under an IRB approval of Stanford University. We thank Joe Altonji, Orazio Attanasio, Pat Bayer, Raj Chetty, Pierre Andre Chiappori, Xavier Gine, Cynthia Kinnan, Christopher Ksoll, Nicola Pavoni, Luigi Pistaferri, Mark Rosenzweig, Matthew Shapiro, Chris Udry, and numerous seminar participants for suggestions. De Giorgi acknowledges financial support from the Spanish Ministry of Economy and Competitiveness, through the Severo Ochoa Programme for Centres of Excellence in R\&D (SEV-2011-0075) and ECO2011-28822, the EU through the Marie Curie CIG grant FP7-631510. The views expressed are those of the authors and do not necessarily reflect the position of the FRBNY or the Federal Reserve System. All errors remain our own.

${ }^{\dagger}$ Angelucci: Michigan [mangeluc@umich.edu]; De Giorgi: Federal Reserve Bank of New York, [giacomo.degiorgi@gmail.com]; Rasul: UCL [i.rasul@ucl.ac.uk].
} 


\section{Introduction}

Households in low-income rural economies face multiple market imperfections. An established literature has studied the causes and consequences of imperfections in credit, insurance and financial markets [Besley 1995]. A key insight to emerge has been the critical role extended families play in allowing households to overcome such market imperfections. In both developing and developed economy settings, such networks have been documented to engage in informal arrangements involving resource flows across network members [Cox and Fafchamps 2008, Attanasio et al. 2015], with such arrangements being enforced through a combination of self-interest, altruism and social pressure [Coate and Ravallion 1993, Platteau 2000].

A prominent strand of this literature examines how extended families enable member households to smooth consumption in response to idiosyncratic income risks [Rosenzweig 1998, Rosenzweig and Stark 1989, Fafchamps and Lund 2000, Foster and Rosenzweig 2001, La Ferrara 2003, Samphantharak and Townsend 2010, Karaivanov and Townsend 2014]. Key to such informal arrangements are that they are reciprocal, involve state-contingent resource transfers towards those facing negative shocks, and they are efficiency enhancing. ${ }^{1}$

A second emerging strand of literature highlights the resource transfers that take place in family networks because of informal kinship taxes being levied on members [Baland et al. 2011, DiFalco and Bulte 2011, Jakiela and Ozier 2016, Squires 2016]. In contrast to risk-sharing transfers, such resource flows not be reciprocal or be channelled towards poorer network members, and most importantly, their existence typically entails efficiency costs through distortions. Such kinship tax distortions have been documented to exist across a range of household decisions including those related to consumption [DiFalco and Bulte 2011], savings [Boltz-Lemmel 2013], labor market participation [Balland et al. 2015], and capital allocations into family enterprises [Squires 2016]. Kinship taxes might also cause households to devote resources hiding their income from network members and thus avoid social obligations altogether [Kinnan 2014, Jakiela and Ozier 2016], and it has been long recognized that the kinds of allocative and productive distortions arising from kinship taxes can lead to poverty traps [Nurske 1953, Lewis 1954].

In this paper we study a third motive for resource flows within family networks. We take as motivation the long tradition in development economics emphasizing that households in agrarian economies are engaged in both consumption and investment/production decisions [Eswaran and Kotwal 1986, Singh et al. 1986, Benjamin 1992]. The interlinkage in these outcomes for household-

\footnotetext{
${ }^{1}$ The seminal works on testing for consumption smoothing are Cochrane [1991], Mace [1991] and Townsend [1994]. Following this line of work, caste-based networks have also been identified as forming informal risk-sharing agreements [Munshi 2011, Mazzocco and Saini 2012, Munshi and Rosenzweig 2016].
} 
firms has been understudied in the twin literatures above, on risk sharing and kinship taxes. We combine insights by studying whether extended family networks pool resources to help relax credit constraints members face and facilitate higher return investments to be undertaken. If so, then in contrast to kinship taxes, this represents a mechanism through which extended family members can eventually escape poverty traps. ${ }^{2,3}$

More precisely, we consider how consumption and investment decisions are interlinked for households subject to imperfect credit markets. We do so for two types of household: those we describe as being connected because they are embedded within a village-based extended family network that pools resources among its members, and those that are isolated and have none of their family members in close geographic proximity and therefore have to rely on their own resources to a greater extent. Relative to isolated households, family networks can relax credit constraints member households face in investment choices. The extent to which family networks foster household investment depends on the interplay between credit markets, asset characteristics and network resources. We contrast less lumpy and collateralizable assets, such as small livestock (poultry) for which credit markets are well functioning, with lumpier and non-collateralizeable investments such as those into human capital, for which borrowing constraints are most severe.

How the increase in resources impacts consumption is closely tied to its impact on investment. If the resources are invested, current consumption may decrease (but future consumption could increase as the returns to investment are realized. In general, the larger the increase in investment, the lower the increase in current consumption for both connected and isolated households.

To take these ideas to data, we exploit the experimental evaluation of the Progresa program, a large-scale anti-poverty policy intervention providing cash transfers to eligible (poor) households in rural Mexico. We empirically document the consumption and investment responses of connected and isolated households to the conditional cash transfers provided by Progresa, exploiting five features of the data.

First, we combine information on the paternal and maternal surnames of household heads and spouses, with the Spanish naming convention to construct family networks in each village. Following the same procedure as our earlier work [Angelucci et al. 2010], we map extended family networks in 500 villages (encompassing over 20,000 households) in rural Mexico. This allows us to

\footnotetext{
${ }^{2}$ Kinnan and Townsend [2012] and Karaivanov and Townsend [2014] are two exceptions in the literature that also jointly study consumption and investment decisions, doing so for Thai household-firms for which rich panel data exists on both dimensions. They document the importance of kin groups for consumption smoothing and easing credit constraints to facilitate household investment.

${ }^{3}$ Other forms of (in-kind) transfer within extended family networks have also been documented and studied, including those used to cement social ties (e.g. ceremonial payments), to pool labor, to share information on labor market opportunities, to create rotating savings and credit associations, and child fostering/adoption [Cox and Fafchamps 2008, Boltz-Lemmel 2013].
} 
distinguish between connected households with a family network in the same village, and isolated households that have none of their family residing in close geographical proximity. ${ }^{4}$

Second, we exploit the randomized research design used to evaluate Progresa: 320 villages were randomly assigned to be treated with Progresa, with the remaining villages retained as controls. Following a partial population experimental design [Moffitt 2001], eligible and ineligible households are identified in both treatment and control villages.

Third, eligible households in treated locations are subject to exogenous and large resource inflows. The average monthly transfer to eligibles corresponds to $36 \%$ of their pre-program monthly food expenditures. More importantly, we document that family networks span eligibility status: some members are eligible while others are ineligible. Among connected and eligible households, over $80 \%$ of their extended family are also eligible. Hence extended family networks as a whole experience substantial resource inflows due to Progresa: on average, these amount to the total monthly income of .60 households in the family network. Given the average network size is 7.5 households, the resource injection provided by Progresa is non-trivial, with the potential to foster large consumption and investment responses among network members if the family pools transfers. These resource inflows can enable some members to undertake non-collateralizable investments, such as those into the human capital of their children, even though the value of transfers any given household receives remains below what is required to self-finance such investments [Schultz 2004, De Janvry and Sadoulet 2006].

Fourth, detailed panel data was collected on both food consumption and investment choices for over 20,000 households every six months pre- and post-intervention, something that remains rare among household panels [Karaivanov and Townsend 2014]. On investment, the data spans a rich array of assets varying in their collateralizability: from holdings of small livestock (such as poultry) for which credit constraints are unlikely to bind, through to entirely non-collateralizable forms of asset such as human capital.

Finally, we are able to study the longer term impacts of resource inflows by exploiting a final wave of data from five years after households first experience receipt of transfers. This sheds light on whether the capacity of family networks to relax credit constraints causes sustained increases in investment, and as the returns to such investments are realized, then feedbacks into higher longer term consumption relative to isolated households.

Under standard assumptions the experimental research design identifies: (i) the average treat-

\footnotetext{
${ }^{4}$ Names and familial linkages have been exploited in studies of intergenerational mobility [Clark et al. 2014, Güell et al. 2015]. In the context of Progresa, Attanasio and Lechene [2014] use a similar algorithm to measure the relative size of husband and wife's extended family in the same village, proxying intrahousehold distributional factors when estimating a conditional demand system.
} 
ment effect (ATE) of resource inflows from a comparison of eligibles in treatment and control villages; (ii) the indirect treatment effect (ITE) of resource inflows from a comparison of ineligibles in treatment and control villages [Angelucci and De Giorgi 2009]. We identify ATEs and ITEs for isolated and connected households. Finally, to exploit the full richness of our data we estimate impacts of exogenous resource inflows at the level of the family network as a whole: this provides a network average treatment effect (NATE) that summarizes how family networks respond to resource inflows, irrespective of which household in the network experiences the resource transfer. We provide NATE estimates on mean consumption and investment, on consumption and investment inequality within networks, and provide novel estimates of how consumption and investment impacts vary with features of the family network architecture.

On consumption we document: (i) eligible connected households significantly increase their food expenditures by 32.7pesos relative to connected households in control villages (this ATE corresponds to a near $23 \%$ increase in food consumption over its baseline level); (ii) ineligible connected households also significantly increase in their consumption by 22.6pesos (this ITE corresponds to a $16 \%$ over baseline levels) relative to ineligible and connected households in control villages, thus providing direct evidence of resource pooling in extended family networks; (iii) among eligibles, the implied marginal propensity to consume (MPC) out of their own resource transfer is .691; among ineligibles the implied MPC to consume out of the transfer received per network member is .639. This implies that for every dollar that accrues to the family network as a whole, food consumption increases by around $65 \notin$ for both households in the network eligible for Progresa transfers and ineligible members of the same network. The implied marginal propensity of families to invest/save out of every dollar is thus around .35; (iv) the NATE estimates indicate consumption inequality within family networks does not change as poorer eligibles experience positive resource increases, consistent with household Pareto weights not changing over the study period.

In contrast, we find that eligible but isolated households have no statistically significant change in their consumption relative to counterfactual isolated households in control villages. Although this impact is imprecisely estimated, it is significantly different from the change in consumption of eligible connected households. Hence there is a need to also consider households' investment outcomes in order to more towards a more complete understanding of how isolated households utilize the resource transfer Progresa represents.

On investment, we find no significant increase in collateralizable assets such as small animals (poultry) among isolated or connected households. This is as expected if there is a well-functioning credit market for such assets.

We find eligible isolated households use a significant fraction of their resource inflow to invest 
into cattle, as has been documented for rural Indian households by Rosenzweig and Wolpin [1993]. Cattle are of intermediate collateralizability, and likely generate earnings from produce sales that co-vary less with their other income streams [Townsend 1994, Bandiera et al. 2016].

In contrast, eligible and connected households significantly increase non-collateralizable investments into human capital as measured by secondary school enrolment rates. In short, less collateralizable forms of investments are significantly responsive to household resources, in line with Karaivanov and Townsend [2014]. We find: (i) eligible connected households significantly increase their schooling investment by $7.5 \mathrm{pp}$ relative to counterfactual connected households in control villages (a 12\% increase over the baseline level); (ii) eligible but isolated households have no such response, and the difference between these impacts is highly significant, despite isolated and connected households receiving similar resource inflows and having the same baseline levels of secondary school enrolment. Given Progresa transfers are insufficient to cover the opportunity cost of secondary schooling, such non-collateralizable investments can only be undertaken by connected households because they are engaged in resource pooling arrangements with family members. These results closely match the findings of Kinnan and Townsend [2012] who report kin networks in Thailand facilitate large investment expenditures through the relaxation of borrowing constraints. Considering the family network as the unit of analysis, our NATE estimates then show that for the average connected household, secondary school enrolment increases by 6.0pp relative to counterfactual family networks in control villages.

Network architecture matters: larger and more closely linked family networks have larger consumption responses, and these same networks are also those with marginally smaller investment responses. These twin results suggest such network features underlie precisely how resources are allocated in informal sharing arrangements [Ambrus et al. 2014, Chandrasekhar et al. 2014].

Finally, we examine the longer term impacts of family networks on consumption and human capital investments using the final wave of panel data from five years after the initial resource transfers. We find: (i) households embedded within family networks have monthly food expenditures that are 19.8pesos higher than for isolated households, corresponding to a $14 \%$ increase over baseline levels; (ii) the longer term gap in secondary school enrolment rates is sustained at $6.4 \mathrm{pp}$, corresponding to just under $10 \%$ of the baseline levels. This suggests the interplay between large resource inflows and resource pooling by family networks might well place them on sustained paths out of poverty and allow them to escape the kinds of poverty trap that have long concerned development economists.

The key contribution of the paper is to highlight an understudied channel for resource flows within extended family networks: to foster investments into non-collateralizeable assets. This 
complements established literatures examining the role that family networks play in allowing households to smooth consumption in the face of idiosyncratic resource shocks, and the role that kinship taxes levied within such networks have on the allocative and productive efficiency of household decisions. Our paper also builds on earlier work studying Progresa. The first generation of Progresa evaluations focused on the average treatment effects on schooling decisions for eligible households [Schultz 2004, Todd and Wolpin 2006, Attanasio et al. 2012]. A second wave of papers have examined the impacts of Progresa on other outcomes including investment and entrepreneurship [Gertler et al. 2012, Bianchi and Bobba 2013]. In most of this work ineligible households have predominantly been exploited to check for spillover or general equilibrium effects of the program operating through prices, labor and credit markets [Angelucci and De Giorgi 2009, Bobonis and Finan 2009, Lalive and Cattaneo 2009].

A third generation of study has exploited information on surnames to pin down social ties between households, and then used this to explore heterogenous treatment responses to Progresa. Our earlier work, Angelucci et al. [2010] did so focusing only on schooling outcomes, and providing suggestive evidence of resource transfers within family networks facilitating such investments. In this paper we consider a richer set of consumption and investment outcomes. In particular our ITE impacts on consumption get to the heart of whether there is resource pooling within family networks or not. We then provide new estimates of consumption and investment responses at the network level, how inequality of consumption and investment in networks is impacted (over an array of asset investments varying in their collateralizability), and how both responses vary as a function of network architecture. The final innovation over the existing literature is to identify longer term impacts of being embedded within family networks on this set of consumption and investment outcomes. This is key to understanding the role that family networks can play in enabling members escape poverty traps. ${ }^{5}$

The paper is organized as follows. Section 2 describes a conceptual framework. Section 3 presents our context, data and empirical methods. Sections 4 and 5 cover the results on consumption and investment respectively. Section 6 examines longer term outcomes. Section 7 concludes by discussing further implications of our findings.

\footnotetext{
${ }^{5}$ Angelucci and De Giorgi [2009] documented the existence of spillover effects of consumption from eligible to ineligible households and identified the likely channel through which this occurred, informal gifts and transfers. However, that paper used no data on family networks and did not study any specific institution through which these transfers occur.
} 


\section{Conceptual Framework}

We now describe how households consumption and investment responses to Progresa differ depending on whether the household is isolated, in that none of their extended family reside in the same village, or whether they are connected, and so embedded within an extended family network in the same village.

\section{$2.1 \quad$ Isolated Households}

We recognize that isolated households may have extended family elsewhere and share resources with them. ${ }^{6}$ However, in the context of responses to Progresa, it is important to note the evaluation data covers a period when the program was still being rolled out in villages across rural Mexico. Hence isolated households are unlikely to have family members in other villages where Progresa had been rolled out. Even if isolated households have eligible family in other Progresa villages in the study period, networks that are more geographically dispersed likely face higher monitoring and enforcement costs to sustain any resource pooling arrangement [Fafchamps and Gubert 2007, Conley and Udry 2010]. ${ }^{7}$

For expositional ease, we describe the consumption and investment responses of isolated households to Progresa assuming there are no resource flows with their extended family (that reside in other villages). We denote the per period resources, consumption and investment of isolated household $h(i)$ as $R_{h(i)}, C_{h(i)}$ and $I_{h(i)}$ respectively. We denote the savings of the isolated household as $S_{h(i)}$. Using the superscript $E$ for eligibles, the following budget accounting identity holds for eligible isolated households:

$$
\Delta R_{h(i)}^{E}=\Delta C_{h(i)}^{E}+\Delta I_{h(i)}^{E}+\Delta S_{h(i)}^{E}
$$

All terms in (1) are defined at the household level. $\Delta R_{h(i)}^{E}$ corresponds to the resource injection due to Progresa that eligible isolated households experience, and is detailed in Section 3 . An increase in resources can increase investment by relaxing credit constraints. This is especially so for lumpy, non-collateralizable assets (such as large livestock and education), which are harder to

\footnotetext{
${ }^{6}$ For example, many Mexican households receive migrant remittances from overseas. However, this is far less the case in the Progresa sample of rural households: for example, Angelucci [2015] documents that in 1998, fewer than $1 \%(4 \%)$ of households in control villages report having a member migrated to the US (elsewhere in Mexico).

${ }^{7}$ On the importance of private information for resource transfers in the context of risk sharing: (i) Ligon [1998] develops an empirical test showing that private information plays an important role in shaping the allocations in village economies in Indian data; (ii) Kinnan [2014] develops a test to distinguish between hidden income, limited commitment and moral hazard as motives for incomplete informal insurance. Using household panel data from rural Thailand, limited commitment and moral hazard are rejected, while there is empirical support for the predictions of hidden income.
} 
borrow against, than more liquid forms of investment (such as small livestock), for which credit markets likely exist. Consumption may increase, decrease, or remain unchanged depending on the effect on investment.

The core analysis in Sections 4 and 5 documents the consumption and investment responses to Progresa of eligible isolated households: $\frac{\Delta C_{h(i)}^{E}}{\Delta R_{h(i)}^{E}}$ and $\frac{\Delta I_{h(i)}^{E}}{\Delta R_{h(i)}^{E}}$, where the former corresponds to the marginal propensity to consume out of Progresa transfers. Finally, we note that our analysis does not focus on the third term, the changes in savings that eligible isolated households experience. Such crowding in/out of resources might well occur [Albarran and Attanasio 2003, Cox and Fafchamps 2008], although such impacts are notoriously hard to measure accurately in most lowincome settings including in this one [Angelucci and De Giorgi 2009]. Our aim is not to establish the identity in (1), but to highlight that resource inflows can be channelled towards consumption and investment purposes, the balance between the two might differ between isolated and connected households, as might the forms of investment undertaken by both types of household. ${ }^{8}$

\subsection{Connected Households}

Connected households are embedded within family networks in the same village, and these networks are assumed to pool resources across members. The underlying motives for such redistribution can relate to consumption smoothing, kinship taxes, or to foster investment. In each case, the relevant unit of analysis is the family network as a whole, denoted $n(c)$ for connected household c. In family networks the following budget accounting identity holds:

$$
\Delta R_{n(c)}=\sum_{n \in n(c) E} \Delta R_{n(c)}^{E}=\sum_{n}\left[\Delta C_{n(c)}+\Delta I_{n(c)}+\Delta S_{n(c)}\right]
$$

where the total resource injection to the family network, $\Delta R_{n(c)}$, sums Progresa transfers across eligible members of the family, denoted $n \in n(c)^{E}$, while on the right hand side we sum over all network members (both eligibles and ineligibles). The total resource inflow to family networks is detailed in Section 3. Thinking through the right hand side highlights three key empirical implications of resource pooling arrangements in family networks.

First, because of resource pooling, there can be consumption responses to Progresa by ineligible households in the extended family, i.e. $\frac{\Delta C_{n(c)}^{N E}}{\Delta R_{n(c)}}>0$ where we use the superscript $N E$ to denote an ineligible member of the family network of eligible household $n(c)$. Without a fully specified micro-founded model of network behavior, we have an ambiguous prediction on the relative change

\footnotetext{
${ }^{8}$ For ineligible isolated households, the LHS of (1) is obviously zero, so that consumption and investment responses can only occur if Progresa causes general equilibrium effects in goods or asset markets. This is testable and something we address below.
} 
in consumption of eligible and ineligible connected households, i.e. $\frac{\Delta C_{n(c)}^{E}}{\Delta R_{n(c)}} \gtreqless \frac{\Delta C_{n(c)}^{N E}}{\Delta R_{n(c)}}$. These two consumption responses correspond to the ATE and ITE of Progresa, estimated in Section 4. Comparing budget accounting identities (1) and (2) also makes clear there is no prediction of the relative consumption responses of eligible isolated and connected households.

The novel motive for resource pooling in family networks is that it enables member households to undertake certain investments they could not otherwise self-finance in the face of imperfect credit markets. Investments into assets that are lumpy and non-collateralizable are especially likely to be aided by resource pooling within extended family networks because there is no credit market to invest in such assets (non-collateralizability) and individual households cannot accumulate enough savings alone to make such investments (lumpiness). The first implication of (2) is thus to examine the investment responses to Progresa over a variety of assets that vary in their collateralizability: the ATE and ITE impacts of Progresa on investment are presented in Section 5. Together, these shed light on whether resource pooling enables richer or poorer households within the network to undertake additional investments.

Finally, to exploit the full richness of our data we estimate impacts of Progresa at the level of the family network as a whole: $\frac{\sum_{n} \Delta C_{n(c)}}{\Delta R_{n(c)}}, \frac{\sum_{n} \Delta I_{n(c)}}{\Delta R_{n(c)}}$. This provides a network average treatment effect (NATE) that summarizes how family networks affect consumption and investment responses to resource inflows among their members, irrespective of which household in the network experiences the resource transfer. We provide NATE estimates on mean consumption and investment, on consumption and investment inequality within networks, and provide novel estimates of how both impacts vary with features of the family network architecture. ${ }^{9}$

\section{Context, Data and Methods}

\subsection{Context}

Progresa is a large-scale government intervention providing cash transfers to poor households conditional on childrens attendance at school, and mother's attendance at health facilities. An experimental research design was implemented to evaluate Progresa: the evaluation involved collecting panel data on 20,000 households every six months in 503 villages between March 1998 and

\footnotetext{
${ }^{9}$ In family networks with only one eligible member, the change in resources (at the network level) is the same as for isolated households. Hence there should be no difference in their investment choices. However, we cannot separately study this subsample of networks because as the descriptives below make clear, the large majority of networks have at least two eligibles in them. Hence when we restrict the analysis to connected households that are the only eligible household in their network, given the small sample sizes involved it is unsurprising that the impacts on consumption and investment are not precisely estimated (and so the finding that such connected households also have no significant increase in their investment is not a very powerful test of the intuition above).
} 
November 1999. The evaluation took place while the program was being scaled-up across villages in rural Mexico. Villages were selected into the evaluation sample if they were sufficiently poor. Credit markets are highly imperfect in this setting, providing scope for extended family networks to play an important role in household's consumption and investment decisions.

To detail the kinds of credit market imperfection prevalent in rural Mexico, we note that in the third wave of data (November 1998) households were asked about the sources and uses of loans/transfers: only $2.8 \%$ households report having outstanding loans, and less than $1 \%$ report having access to formal credit. Among those using formal loans, $66 \%$ of households report using them to finance investment into livestock, agriculture or businesses. In contrast, among those using informal credit, $76 \%$ of households report using such loans to finance consumption and other emergencies. ${ }^{10}$

To understand whether Progresa transfers could be used to finance investments into noncollateralizable assets, we note that while the average monthly transfer to eligibles is non-negligible, corresponding to $35 \%$ of pre-program monthly food consumption expenditures, this magnitude remains far below what is required for households to self-finance non-collateralizable investments into human capital: for example, Schultz [2004] finds that the value of transfers corresponds to between one half to two thirds of the full time child wage in the survey villages; De Janvry and Sadoulet [2006] argue that transfers correspond to around $40 \%$ of what children of the same age would earn. In either case, the transfers do not fully compensate for foregone earnings of secondary school aged children employed full time in the labor market. ${ }^{11}$

In the pre-program period households were asked the main reason why children did not attend school: for those with children aged between 6 and 18, 39\% cited a lack of financial resources, and a further $11 \%$ cited needing the child to work or help at home. Hence if multiple households in the same family network were to be in receipt of Progresa transfers, and these households pooled resources, it would be possible for them to channel resources towards some network members and enable such investments into non-collateralizable assets to occur.

Of the sampled villages, 320 were randomly assigned to receive Progresa from May 1998, and 183 were assigned as controls. Two pre-program survey waves were conducted (October 1997,

\footnotetext{
${ }^{10}$ In other low income settings, such informal arrangements have been documented to include the use of statecontingent informal loans [Udry 1994], or gifts and other quasi-credit arrangements [Platteau 1997].

${ }^{11}$ Relatedly, Todd and Wolpin [2006] note that to the extent that children engage in work in family enterprises/farms, the opportunity cost of their labor is not even the market wage but their marginal product in family enterprises/farms: that is even harder to measure. Finally, Attanasio et al. [2011] also present evidence suggesting the opportunity cost of schooling is not fully offset by the value of transfers: more precisely they document using a structural model, that a revenue neutral change in the program that would increase the grant for secondary school children while eliminating for the primary school children would have a substantially larger effect on enrollment of the latter, while having minor effects on the former.
} 
March 1998). The other waves occur post-intervention (November 1998, May 1999, November 1999). To study the longer term impacts on consumption and investment outcomes of connected versus isolated households, we exploit a final wave of data from November 2003. Finally, we match our panel data to administrative records detailing the potential and actual transfers provided to each household. Table A1 describes the key variables and survey waves used. ${ }^{12}$

In 1997 households were classified as either being eligible (poor) or ineligible (not poor) for Progresa transfers according to a household poverty index, designed to give relatively greater weight to correlates of permanent rather than current income. Around three quarters of households are classified as eligible: as shown later, this implies the typical family network will have many eligible members. ${ }^{13}$ The transfers correspond to exogenous increases resources to eligible households, with uncertainty as to whether transfers would be available beyond 1999 .

In family networks, we observe eligibles and ineligibles. This allows us to measure whether the consumption responses of households in a network are the same irrespective of which network member received the transfers $\left(\frac{\Delta C_{n(c)}^{E}}{\Delta R_{n(c)}}, \frac{\Delta C_{n(c)}^{N E}}{\Delta R_{n(c)}}\right)$; and for non-collateralizable investments, to examine whether poorer (eligible) or richer members of the network are able to undertake such investments when their network experiences resource inflows $\left(\frac{\Delta I_{n(c)}^{E}}{\Delta R_{n(c)}}, \frac{\Delta I_{n(c)}^{N E}}{\Delta R_{n(c)}}\right)$. There is variation in the monetary value of transfers households (and therefore networks) are eligible for depending on a non-linear relationship with the demographic composition of children pre-program: transfers conditional on school enrolment are larger for higher school grades, and for girls within any given grade. ${ }^{14}$

\subsection{Constructing Family Networks}

To identify the extended family links between households in the same village we use the same procedure described in Angelucci et al. [2010], exploiting information on: (i) surnames provided in the third wave of data; (ii) the naming convention in Mexico. As the Progresa evaluation data represents a near census of households in each village, we construct complete extended family

\footnotetext{
${ }^{12}$ Control villages began receiving Progresa transfers in December 1999. In 1997, eligibles in control villages were informed they would receive the program from the end of 1999 conditional on them still being eligible and the program continuing. We do not find any evidence households in treated villages are more likely to attrit between October 1997 and November 2003, and nor is there evidence of differential attrition of connected households in treated villages relative to control villages.

${ }^{13}$ Households were informed that their eligibility status would not change at least until November 1999, irrespective of any variation in household income. A group of households, known as densificados, had their eligibility status reclassified from non-eligible to eligible in October 1998. A non-random subset of them began receiving Progresa transfers in treatment villages prior to November 1999. As no precise algorithm exists to determine which densificados received transfers in treatment villages, no counterfactual set of households exists for them in control villages. Hence we do not consider such households in our analysis of consumption and investment outcomes.

${ }^{14}$ By November 1999 the bimonthly transfer ranged from 160 pesos for third grade, to 530 (610) pesos for boys (girls) in ninth grade. The total amount received bimonthly by a household cannot however exceed 1500 pesos.
} 
network structures for all 20,000 households in over 500 villages. ${ }^{15}$

Mexicans use two surnames: the first is inherited from the father's paternal lineage and the second from the mother's paternal lineage. For example, former Mexican president Vicente Fox Quesada would be identified by his given name (Vicente), his father's paternal name (Fox) and his mother's paternal name (Quesada). Respondents were asked to provide the: (i) given name; (ii) paternal surname; and, (iii) maternal surname, for each household member. Hence couple headed households have four associated surnames: the paternal and maternal surnames of the head, and the paternal and maternal surnames of his wife. ${ }^{16}$

Figure 1 illustrates the algorithm used to link households. To define each link, we use information on two of the four surnames. Consider household $\mathbf{A}$ at the root of the family tree. The head of the household has paternal and maternal surnames $F 1$ and $f 1$ respectively. His wife has paternal and maternal surnames $F 2$ and $f 2$ respectively. ${ }^{17}$ The children of the couple in household A will adopt the paternal surnames of their father $(F 1)$ and mother $(F 2)$. Hence we identify a parent-son family link between households $\mathbf{A}$ and $\mathbf{B}$ if: (i) the paternal surname of the head in household $\mathbf{B}$ is the same as the paternal surname of the head in household $\mathbf{A}(F 1)$; and, (ii) the maternal surname of the head in household $\mathbf{B}$ is the same as the paternal surname of the spouse in household $\mathbf{A}(F 2)$. Parent-daughter family-links can be similarly identified. Moreover, family links between siblings can also be identified. For example, the heads of households $\mathbf{B}$ and $\mathbf{C}$ are identified to be brothers if they share the same paternal and maternal surnames. We impose the following restrictions when defining family links: (i) inter-generational links exist when the relevant individuals have at least 15 years age difference, and no more than 60 years age difference between mother and child; (ii) intra-generational links exist when the individuals have at most 30 years age difference.

\footnotetext{
${ }^{15} \mathrm{~A}$ concern arises from the surnames data being measured in the first wave post-program, in that households may endogenously respond to the program by changing household structures. In particular, by artificially forming new households in order to increase the number of eligibles in the family. This concern is ameliorated by the fact that the register of eligibles was drawn up at baseline, and only households recorded to be eligible at that point were later entitled to receive transfers.

${ }^{16}$ The wording of the question in Spanish is, "Digame por favor el nombre completo con todo y apellidos de todas las personas que viven en este hogar, empezando por (jefe del hogar) - (i) nombre; (ii) apellido paterno; (iii) apellido materno". We cleaned the surnames data as follows: (i) we removed non-alphabetical characters, replaced "Sin Apellido" (no surname) with missing values, and corrected some obvious typos based on intra-household surname checks; (ii) we imputed a small number of missing female surnames from wave 2; (iii) we verified surnames using the same information from wave 5, and verified the relationship to the household head using wave 1 data. No information on surnames is available in the first wave of data. The head of household is originally defined to be the main income earner. In a very small number of cases the head of a couple headed household is reported to be a women. To keep clear the exposition, we redefine the head to be male in such cases.

${ }^{17}$ Paternal (maternal) surnames are indicated in upper (lower) case. First names are not shown as they are irrelevant for the matching algorithm. In Anglo Saxon countries, $F 1$ corresponds to the family name and $F 2$ corresponds to the spouse's maiden name.
} 
We thus identify households with at least one first-degree relative in the village, as well as the entire network of first-degree relatives. Hence all the households in Figure 1 would belong to the same first-degree extended family network, even though some are first cousins, or linked across two generations. Figure 1 shows all households to be couple headed to ease the exposition. To deal with the $15 \%$ of households that are single headed we use additional information on the gender of the head to identify family links. Although such single headed households are then used to construct the extended family networks, we focus our analysis of consumption and investment outcomes on the $85 \%$ of households that are couple-headed. ${ }^{18}$

There are of course limits to our algorithm. For example, two households headed by cousins will not be recorded as belonging to the same extended family unless both sets of parents are present. Angelucci et al. [2010] provides more descriptive evidence on surnames in this setting, and provides external validity to the created links using data from the Mexican Family Life Survey (MxFLS). More precisely, we show how the number of first-degree relatives rural households have alive in any location, as recorded in the MxFLS, compares, on average, to the number of relatives our algorithm suggests reside in the same village for rural households. ${ }^{19}$

\subsection{Networks}

Panel A of Table 1 shows that $80 \%$ of households are connected, so have at least one other extended family member heading their own household in the village. Thus $20 \%$ of households are isolated in that none of their extended family members reside in the same village. There are on average 7.5 members in each family network, highlighting the potential importance of informal resource pooling arrangements within families. Our analysis among connected households is based on 1379 (817) unique family networks in treatment (control) villages covering 10559 (6471) households.

\footnotetext{
${ }^{18}$ There are additional limits involving single headed households. Consider links from household $i$ to a single headed household $j$. As Figure 1 shows, the fact that household $j$ is single headed does not affect the construction of links from the head and spouse of household $i$ either to their children or to their siblings. However, links from the head (spouse) of household $i$ to the household of his (her) parents can only be identified if both his (her) parents are alive and resident together because this particular link is identified using information from household $j$ on the paternal surnames of both the head and spouse. However this is unlikely to be a major issue: we note that female widows aged above 40 are $37 \%$ more likely to live as a dependent within a household, rather than head their own household, relative to a similar married woman. These single parents are recorded in the household roster.

${ }^{19}$ There are a number of potential forms of measurement error in surnames that we can check for, as described in Angelucci et al. [2010]. The first arises from the convention that women change their paternal surname to their husband's paternal surname at the time of marriage (although the wording of the survey question specifically asks respondents to name the paternal and maternal surname of each household member). In $5.8 \%$ of households is the spouse's maternal surname recorded to be the same as her husband's paternal surname. Second, if the male head is the respondent, he may not recall his wife's maternal surname and simply replace it with her paternal surname (as his children only inherit his wife's paternal surname). This occurs in only $4.9 \%$ of households. A final circumspect case is households in which the paternal and maternal surnames of both the head and spouse are all reported to be the same. This occurs for $1.6 \%$ of households, and drops to $.5 \%$ if we exclude households with the most common surname. There are no differences in the incidence of these potential errors between treatment and control villages.
} 


\subsection{Consumption and Investment at Baseline}

Panel B of Table 1 presents data on food consumption, measured in adult equivalents. Food consumption is based on seven day recalls over 36 food items (Table A1 provides further details). Monthly food expenditures are 144pesos. Given a daily poverty line of $\$ 1.25,70 \%$ of households lie below this threshold if we aggregate per capita food and non-food expenditures. Figure 2A shows the distribution of daily per capita expenditures across couple headed households pre-program. This reiterates the absolute poverty these households experience, and the fact they lack resources to finance many forms of investment.

Panel $\mathrm{C}$ focuses on household investments, split between livestock and schooling. The collateralizability of such assets varies between these extremes depending partly on the transactions costs lenders face in reselling assets used as collateral in the case of borrower default. To recognize this continuity in asset collateralizability, among livestock we consider the division between investments in small animals (chickens, rabbits, pigs and goats) and larger animals (donkeys, horses, cows and oxen). Over $80 \%$ of households own some form of small livestock, typically poultry. The thick market for such assets makes small livestock highly collateralizable. In contrast, only around $40 \%$ of households own larger animals such as cattle and there are high transactions costs from their resale. Hence larger animals can be classified as being of intermediate collateralizability. The value of owned livestock is almost identical across isolated and connected households pre-program, as are the separate values of owned small and large livestock. ${ }^{20}$

On entirely non-collateralizable human capital investments, primary enrolment rates are above $90 \%$ for households at baseline, so that most choose to send their children to school even absent Progresa. In contrast, secondary school enrolment rates are lower, at around $65 \%$. Hence this is the relevant margin of schooling investment choice. As the value of transfers is insufficient to offset credit constraints related to this investment, for poorer (eligible) connected households, the ability to pool resources within the family network is key for such investments to be undertaken.

Column 3 in Table 1 shows tests of equality between connected and isolated households for each characteristic. At baseline, the two types of household are not significantly different on most dimensions, suggesting they have similar preferences over consumption and investment. It is plausible that the Progresa program is the first time the majority of households in these communities simultaneously experience a large increase in resources, and thus allow resource pooling families

\footnotetext{
${ }^{20}$ Fafchamps and Pender [1997] estimate a structural model of irreversible investment decisions and find that poor farmers fail to undertake profitable investments that they could in principle self-finance, because the nondivisibility of these investments makes it infeasible to self-finance. Rosenzweig and Wolpin [1993] also emphasize the irreversibility of investment as leading to the choice of investments into bullocks rather than irrigation equipment. We can think of this as being another important difference between small and large livestock.
} 
to overcome borrowing constraints and spark non-collateralizable investments. To see if this can be studied using the experimental research design of Progresa, Columns 4 and 5 show that within connected and isolated households, the samples are mostly balanced on outcomes across treatment and control villages. Hence we can exploit the randomization to identify the causal impact of resource inflows on connected and isolated households. The exception is for primary enrolment rates between connected and isolated households, albeit the absolute difference is small (93\% versus $91 \%$ ). To account for any pre-treatment differences in household preferences for schooling, we thus control for the household's primary school enrolment rate at baseline when estimating investment responses related to human capital outcomes (secondary schooling and child labor).

\subsection{Transfers}

We now describe data from administrative records on Progresa transfers that we match to the main household panel. The first row in Panel D shows that just over $70 \%$ of households are eligible. On the availability of transfers from extended family members, among connected and eligible households, over $80 \%$ of their extended family are also eligible. For ineligible (hence less poor) households, just over $50 \%$ of their extended family are eligible: that this share is lower for ineligibles is unsurprising given there is less variation in permanent income within than across extended families.

The remaining rows in Panel D show the value of these potential transfers to connected households, measured in survey wave 3 (November 1998). Potential transfers are those that would accrue to eligible households if they perfectly complied with the program's conditionalities. If we assume such transfers are not shared with others, the average potential transfer available per adult equivalent in eligible households is 53pesos per month. The next row considers the other case where potential transfers are spread evenly across all family network households: in this scenario the average potential transfer available per adult equivalent in connected households is 39pesos per month. Column 3 confirms there are no significant differences between connected and isolated households in terms of their eligibility status or the value of transfers they can potentially receive. Nor do we find any significant difference in the value of potential transfers available to connected and isolated households. ${ }^{21}$

To benchmark the magnitude of these transfers, we first note that potential transfers represent around $36 \%$ of food consumption expenditures for eligible isolated and connected households. If we consider family networks in which transfers are spread evenly across eligibles and ineligibles,

\footnotetext{
${ }^{21}$ We use the equivalence scale estimated by Di Maro [2004] from the same data. This sets a scale of one for members 18 or older, and .73 otherwise. We use the monthly Bank of Mexico CPI series to deflate monetary values.
} 
the potential transfers available per household correspond to $27 \%$ of the value of household food consumption (in adult equivalent terms). If the potential transfers from Progresa were entirely used for consumption, $15 \%$ of eligible households could be moved above the poverty line, as shown by the second distribution in Figure 2A; taking into account potential per capita resource transfers from eligible network members, then $19 \%$ of connected but ineligible households could be moved above the poverty line, as shown by the third distribution in Figure 2A (noting that ineligibles have higher levels of consumption to begin with).

As Progresa transfers are conditional on childrens regular school attendance and given high baseline enrolment rates, most eligibles would receive transfers even absent any change in enrolment behavior. Such de facto unconditional cash transfers of course provide an income effect that enables households (connected or isolated) to raise consumption and investment without any change in actual schooling behavior.

On the actual value of monthly transfers received, we find that: (i) transfers accruing to connected and isolated households are: for example in survey wave 3 (November 1998) they correspond to 119 (112) pesos for connected (isolated) households; (ii) between November 1998 and November 1999 (survey waves 3 to 5), the value of actual transfers received correspond to around $11-18 \%$ of the value of household food consumption. We can also benchmark these actual transfers against household and network levels of monthly income. For example, household monthly income among eligible connected (isolated) households is 1232 (1286) pesos. Hence, for connected eligibles, actual Progresa transfers correspond to the total monthly income of $10 \%$ of eligible households in the family network. Given networks on average contain 7.5 households of which many are eligible, this again shows the resource injection provided by Progresa to be non-trivial. In short there is scope for networks to experience resource inflows large enough so as to help some of their members to overcome binding credit constraints on non-collateralizable investments. ${ }^{22}$

\subsection{Empirical Method}

Consider outcome $y_{h v t}$ for household $h$ in village $v$ in survey wave $t$. Food consumption outcomes are measured in pesos per adult equivalent. The investment outcomes considered are livestock ownership (small, large animals) and secondary schooling, representing investments of high, intermediate and low levels of collateralizability respectively. We define three indicators: (i) $D_{h}=E$ if household $h$ is eligible, and $D_{h}=I$ if ineligible; (ii) $P_{v t}=1$ if Progresa is in place in village $v$ in survey wave $t$, and zero otherwise; (iii) $N_{h}$ is a time-invariant characteristic indicating whether

\footnotetext{
${ }^{22}$ Household income is defined as labor income (summed over all household members), plus income from informal activities, pension receipts, interest and payments from rentals, plus any other source of income. All figures cited are measured in November 1998 (survey wave 3).
} 
household $h$ is connected $\left(N_{h}=1\right)$ or isolated $\left(N_{h}=0\right) .{ }^{23}$

Focusing first on the response of eligible couple-headed households $\left(D_{h}=E\right)$ to the resource inflow Progresa provides, we estimate the following OLS difference-in-difference specification, where we superscript the coefficients of interest with the eligibility status of households:

$$
y_{h v t}=\beta_{0}+\beta_{1} N_{h}+\beta_{2}^{E} P_{v t}+\beta_{3}^{E}\left(P_{v t} \times N_{h}\right)+\boldsymbol{\beta}^{\prime} \mathbf{X}_{h v 0}+v_{h v t}
$$

$\mathbf{X}_{h v 0}$ includes baseline characteristics of the head, household, and village, and standard errors are clustered by village (the level at with Progresa operates) to capture common shocks across households. We consider changes in consumption and investment over the same period, utilizing surveys from March 1998, May 1999 and November 1999. Our working sample of eligibles for consumption outcomes covers over 10,000 households in these survey waves. ${ }^{24}$

As take-up is near universal, estimating (3) among eligibles, $\beta_{2}^{E}$ measures the average treatment effect (ATE) for isolated households, $\beta_{2}^{E}+\beta_{3}^{E}$ is the ATE for connected households. These are identified solely by exploiting the randomization across villages, assuming no spillovers across villages. Hence for each type of household in treated villages, the counterfactual is the same type of household in control villages. The evidence in Table 1 shows the eligibility, consumption and investment characteristics of connected and isolated households to be well balanced at baseline across treatment and control villages.

These ATE estimates for isolated and connected households measure the causal impact of resource shocks on consumption and investment. The difference between the two ATE estimates $\left(\beta_{3}^{E}\right)$ is informative of the causal impact of being connected relative to being isolated when resources increase, under the additional assumption that being connected $\left(N_{h}=1\right)$ is uncorrelated with unobservables driving $y_{h v t}$. While Table 1 previously suggested there are few differences on observables between both household types, this difference is less central to our analysis. We focus predominantly on the main ATE estimates that exploit only the randomization and identify

\footnotetext{
${ }^{23}$ Although in the very long run we expect family networks to adjust through marriage, mortality and migration, our analysis treats networks as fixed. A nascent empirical literature studies whether financial market innovations lead to changes in social network structures [Banerjee et al. 2014, Binzel et al. 2014].

${ }^{24} \mathbf{X}_{h v 0}$ includes the following controls (measured at baseline): age of the household head, household size by age brackets (0-7, 8-14, 15-19, more than 19), the standardized household wealth index, village marginalization index, and region dummies. To account for one imbalance at baseline we additionally control for the household's primary school enrolment rate at baseline when we consider investment outcomes. We do not utilize data from the third survey wave (November 1998) as in many treated villages, the program had only just started operating in some treated locations, and was not fully operational in other treated villages. Including this data wave thus leads to slightly less precision in some estimates, and this cannot be properly dealt with absent administrative records detailing the exact time at which transfers began to be implemented in each treated village. For comparability, we use the same waves of data for our baseline consumption and investment results. However as Table A1 details, consumption specifications could also be run using the first wave of data (October 1997) and the results are qualitatively unchanged if we do so.
} 
how households with a given family structure respond to resource inflows. Finally, we note that for consumption outcomes we can derive the implied marginal propensity to consume out of the household's own resource inflow by dividing the ATE estimate (as consumption outcomes in (3) are in levels), by the actual transfer received by the eligible household, where both are measured in peso adult equivalents:

$$
\text { Implied Own MPC }=\frac{\text { ATE }}{\text { Household's Own Transfer }} .
$$

To understand whether the consumption and investment outcomes of connected but ineligible households are impacted when others in their extended family network receive resource inflows, our second set of results estimate (3) among ineligibles $\left(D_{h}=I\right)$. The corresponding coefficients of interest are: $\beta_{2}^{I}$, that measures the indirect treatment effect (ITE) for isolated households, and $\beta_{2}^{I}+\beta_{3}^{I}$, the ITE for connected households [Angelucci and De Giorgi 2009]. These consumption estimates get to the heart of whether there is resource pooling within family networks, and are based of a working sample of over 4,000 ineligible households across the same three survey waves as for the ATE impacts described above.

Two further points are of note. First, these ITE estimates are identified exploiting only the randomization across villages. For ineligible isolated households that do not pool resources with others in the village, consumption should be unaffected by the resource inflows experienced by others $\left(\beta_{2}^{I}=0\right)$. However, given $75 \%$ of households are eligible for transfers, these represent a large resource inflow to the village economy as a whole. As such, the program might have general equilibrium effects operating through wages or aggregate demand channels. If so then $\beta_{2}^{I} \neq 0$ and we can examine this directly. Second, for the consumption outcomes of ineligibles we can derive the implied marginal propensity to consume out of the family network's entire resource inflow by dividing the ITE estimate by the actual transfer received per network member, where both are measured in adult equivalents:

$$
\text { Implied Family MPC }=\frac{\text { ITE }}{\text { Family Network's per Household Transfer }} .
$$

The final stage of empirical analysis for consumption and investment outcomes exploits the full richness of our data and estimates impacts of resource increases at the level of the family network as a whole: hence the unit of analysis is network $n$ in village $v$ in wave $t$. Recall that there are around three family networks per village, and we focus on those networks with at least one eligible household within them. We then estimate an OLS difference-in-difference specification analogous 
to (3) but aggregated to the level of each network:

$$
y_{n v t}=\delta_{0}+\delta_{1}^{N} P_{v t}+\boldsymbol{\delta}^{\prime} \mathbf{X}_{n v 0}+\epsilon_{n v t},
$$

where the network level controls $\mathbf{X}_{n v 0}$ are those used in the core analysis, but averaged at the network level. These estimates are based on a working sample of over 1600 family networks across the same three survey waves described above. We refer to the estimated parameter of interest,

$\widehat{\delta}_{1}^{N}$, as the network average treatment effect (NATE). Of course, when $y_{n v t}$ is the network average of the earlier household outcomes considered, $y_{n v t}=\frac{1}{n_{h}} \sum_{h \in h(n)} y_{h v t}$, then the NATE is a weighted average of the ATE and ITE estimates for connected households. However, estimating (6) allows us to investigate beyond mean impacts and also consider how resource increases to the network impact consumption inequality within networks.

\section{Consumption}

\subsection{Direct Effects on Eligibles}

We first present our findings on consumption following the three-step sequencing described above. Column 1 of Table 2 considers the sample of eligible households $\left(D_{h}=E\right)$ and presents ATE estimates from (3), measuring how eligibles are impacted by their own increase in resources. This shows that for food consumption expenditures: (i) eligible isolated households have an increase of 12.9pesos in their consumption relative to counterfactual eligible and isolated households in control villages: while this difference is not statistically significant, it is not precisely estimated either, so that we cannot rule our relatively large consumption responses of eligible isolated households to Progresa; (ii) connected households significantly increase their consumption by 32.7 pesos relative to connected households in control villages; (iii) the difference in these ATE estimates between

connected and isolated households is significant at the $1 \%$ level $\left(\widehat{\beta}_{3}^{E}>0\right)$, despite both types of household having similar levels of food consumption at baseline and receiving similar valued potential transfers (as Table 1 showed).

The foot of Column 1 reports the implied MPC to consume out of own transfers is .691 for connected households, and only .276 for isolated households. Among connected households, the implied short run MPC out of transfers is of comparable magnitude to other studies [Bhalla 1979, Musgrove 1979, Paxson 1992, Gertler et al. 2012]. The implied MPC suggests around $30 \%$ of received transfers are channelled to alternative uses among connected households. We later examine the extent to which resource pooling within families allows connected households to 
undertake non-collateralizable investments. For isolated households, given the weaker consumption response to transfers, it is vital to consider investment outcomes to obtain a more complete picture of how such households choose to utilize the resource inflow Progresa represents. ${ }^{25}$

\subsection{Indirect Effects on Ineligibles}

Column 2 in Table 2 considers the sample of ineligible households $\left(D_{h}=I\right)$ and presents ITE estimates from (3). This shows that for food consumption: (i) ineligible isolated households have no significant change in their consumption relative to counterfactual isolated households in control villages $\left(\frac{\Delta C_{h(i)}^{E}}{\Delta R_{h(i)}^{E}}=0\right)$; (ii) ineligible connected households significantly increase their consumption by 22.6pesos (or by $15 \%$ of their baseline level) relative to counterfactual connected and ineligible households in control villages $\left(\frac{\Delta C_{n(c)}^{E}}{\Delta R_{n(c)}}>0\right.$ ); (iii) the zero consumption response among ineligible isolated households $\left(\widehat{\beta}_{2}^{I}=0\right)$ is consistent with an absence of general equilibrium effects of the program, in line with existing evidence. ${ }^{26}$

Comparing the ITE and ATE estimates for connected households, we cannot reject the null that these are the same size, although the ATE point estimate is $44 \%$ higher than the ITE. Comparing the implied MPCs in Columns 1 and 2, we again see a striking similarity between how on the margin, eligible and ineligible households convert additional resources into consumption: the MPC derived from the ATE is .691; the MPC derived from the ITE is similar at .639. In short, this implies that for every dollar that accrues to the family network as a whole, this leads to a $65 \phi$ increase in food consumption and this effect is similar for eligible and ineligible households in the network. This is clean evidence in favor of resource pooling within the extended family network, that has not previously been documented in the context of Progresa.

Figure 2B graphs how the distribution of food consumption expenditures are shifted for both eligibles and ineligibles, and that a substantial share of both sets of households are brought above the global poverty line by the interplay of the program and resource pooling by extended families.

\footnotetext{
${ }^{25}$ Bhalla [1979] reports an MPC of .61 for rural India; Musgrove [1979] reports MPC $\in$ [.78 - .88] for individuals residing in urban areas in various countries in Latin America. Exploiting rainfall shocks, Paxson [1992] documents $\mathrm{MPC} \in[.56-.84]$ for rice farmers in Thailand. Finally, Gertler et al. [2012] report an MPC of .74 in the Progresa evaluation data when all eligibles are considered together: our results highlight the considerable heterogeneity in MPCs by household type that underlie this, and that this difference is best understood by considering both consumption and investment outcomes. Albarran and Attanasio [2003] present evidence that private resource transfers are crowded-out by the receipt of Progresa transfers and so our implied MPC is likely an underestimate.

${ }^{26}$ Angelucci and De Giorgi [2009] provide evidence that local food prices do not change significantly over time between treatment and control villages suggesting that any ITEs are not being driven by general equilibrium effects of Progresa. In the context of the PAL cash transfer program in Mexico, Cunha et al. [2014] report no evidence of general equilibrium effects in villages except for the most remote villages, likely because such locations are least integrated with markets.
} 


\subsection{Network Effects}

We now focus on the family network as the relevant unit and estimate (6) for networks with at least one eligible household in them. The parameter of interest, $\delta_{1}^{N}$, is identified exploiting the experimental research design. Table 3 presents the results. Column 1 shows that average food consumption in family networks in treatment villages is 15.6pesos higher than in such networks in control villages, a significant difference at the $5 \%$ level.

Column 2 shows the effect of resource increases on network consumption inequality, as measured by the standard deviation in cross sectional log consumption in the network, $y_{n v t}=\operatorname{sd}\left(\log y_{h v t}\right)_{h \in h(n)}$. This shows family networks in treated villages have the same levels of inequality as counterfactual networks in control villages. This result has two important implications: first, it shows that in the short run, family networks partially undo transfer programs aimed at assisting the poor. Indeed, if all households were in a family network, transfer-based poverty programs would have little impact on short run inequality. Second, the result suggests the Pareto weight of connected households is unchanged over the study period.

Finally, we explore how the architecture of family networks impacts consumption responses. To do so, we estimate (6) allowing for an interaction between the Progresa dummy $\left(P_{v t}\right)$ and network characteristics $\left(N_{n}\right)$. We first consider network size, as it has been argued that in some cases larger networks can better smooth consumption [Munshi and Rosenzweig 2016]. We split family networks into those above/below the median size and summarize our findings in the first panel of Figure 3A. This shows the earlier effects are largely driven by larger family networks (despite the average transfer per adult equivalent being the same in small and large networks): in treated villages, the response in mean food expenditures is 26.9pesos, that is significantly greater than the response among smaller than median sized networks in the same village.

The remaining panels of Figure 3A explore how other dimensions of network architecture interplay with consumption responses of family networks that experience resource inflows and show: (i) networks that are above median diameter (and so likely span more generations) have significant consumption responses; (ii) more highly linked networks (as measured by their closeness centrality) have significant consumption responses. In short, for a given transfer, larger and more linked networks appear able to achieve higher levels of consumption. This opens up interesting avenues for future research, as in Ambrus et al. [2014] and Chandrasekhar et al. [2014], for better understanding the link between network architectures and household consumption. 


\section{Investment}

\subsection{Direct Effects on Eligibles}

To fully characterize household responses to resource inflows, we now analyze investment outcomes. We first present ATE estimates from (3) using eligibles, considering three types of investment: those into small livestock (e.g. poultry) that can be thought of as highly collateralizable, those into childrens' human capital in the form of secondary schooling, that are considered to be of low collateralizability, with investment into larger livestock (e.g. cattle) somewhere between these extremes. As Table 1 showed, given that rates of livestock ownership are over $80 \%$, there is not much scope for the extensive margin for such investments to change. Hence we consider the impacts of resource increases on the peso value of owned livestock. We do so for over 9, $000(7,000)$ eligibles when examining small (large) livestock investments. We measure secondary school investment as the share of 11-16 year old children in the household that are attending school, defined for 5, 800 eligibles that have children aged 11-16.

Column 1 of Table 4 shows that for small livestock: (i) neither eligible isolated nor connected households have any significant change in the value of owned livestock relative to counterfactual households in control villages; (ii) the difference in these ATE estimates between connected and

isolated households is not significant $\left(\widehat{\beta}_{3}^{E}=0, \mathrm{p}\right.$-value $\left.=.55\right)$. Hence as expected, resource inflows to households have no impact on such collateralizable investments because credit market imperfections are not so severe that such forms of investment cannot be financed.

Column 2 repeats the analysis for investment into large animals: (i) eligible isolated households significantly increase their holdings of such animals relative to counterfactual households in control villages [p-value $=.067$; ;ii) eligible and connected households do not undertake such investments. To gauge whether the magnitude of the impact on isolated households by November 1999 is plausible, we note that the 887peso increase in the value of cattle owned corresponds to around 4.6 months worth of transfers the median isolated household would have received up until then. By considering investment outcomes, we are able to explain the otherwise puzzling weak consumption response of eligible isolated households to resource inflows documented in Table 2. More precisely, these investment responses to Progresa by isolated households are consistent with the lack of a statistically significant consumption responses documented in Table 2: isolated eligible households use their transfers to buy large livestock, since, presumably, it is difficult for them to finance such investments through loans (recall that less than $3 \%$ of all households report having outstanding loans at baseline).

These findings suggest that relative to connected households, eligible isolated households might 
use some fraction of their transfers to invest into cattle. By considering investment outcomes, we begin to explain the otherwise puzzling weak consumption response of eligible isolated households to resource inflows found in Table 2. Isolated eligible households might well use their transfers to buy large livestock, since, presumably, it is difficult for them to finance such investments through loans (recall that less than $3 \%$ of all households report having outstanding loans at baseline). Moreover, such investments likely generate earnings streams from the sales of livestock produce that are less correlated to other income streams. ${ }^{27}$ Of course, if negative resource changes have symmetric effects on isolated households, then these findings link to Rosenzweig and Wolpin [1993], who first identified that larger draft animals are sold off by households in economic distress, and validates the theoretical concern raised by Chetty and Looney [2006] that the ability of households to smooth consumption does not imply there are zero welfare costs of income risk. ${ }^{28,29}$

Column 3 repeats the analysis for investment into secondary schooling. We find a starkly different pattern of responses from those into livestock, that indeed more closely resembles the ATE impacts for food consumption: (i) isolated households that experience a resource inflow have no significant change in their secondary school enrolments relative to isolated households in control villages; (ii) connected households significantly increase their schooling investment by $7.5 \mathrm{pp}$ relative to counterfactual connected households in control villages (corresponding to a $12 \%$ increase over the baseline level); (iii) the difference in these impacts is significant at the $1 \%$ level despite both isolated and connected households receiving resource inflows of similar amounts and having the same levels of secondary school enrolment at baseline (Table 1). Given the value of Progresa transfers is insufficient to cover the full opportunity cost of secondary schooling, such non-collateralizable investments can only be undertaken by connected households rather than isolated households because they are engaged in resource pooling arrangements with extended family members. This build on the evidence presented in Angelucci et al. [2010] that first highlighted

\footnotetext{
${ }^{27}$ In support of this, we note that $50 \%$ of heads of isolated households report being a daily wage laborer as their main occupation pre-program. Such workers face the highest income earnings volatility relative to other occupations in agrarian economies, with earnings generated from livestock produce considered to be among the least volatile [Townsend 1994, Bandiera et al. 2016]. Hence there would be a desire among these households to diversify income streams towards those arising from livestock.

${ }^{28}$ The important issue raised by Chetty and Looney [2006] is that if households are highly risk averse then consumption smoothing might be achieved through behaviors that reduce household's long run welfare, such as taking children out of school or selling productive assets. Hence, focusing exclusively on how consumption responds to idiosyncratic income shocks is insufficient to fully characterize the welfare costs of income risk. Rosenzweig and Wolpin [1993] long provided evidence of precisely this type of interlinkage for rural Indian households: they show when farm profit realizations are low, such households are forced to sell off bullocks to smooth consumption.

${ }^{29}$ To check for suggestive evidence that isolated households indeed have higher consumption variability that connected households and so might be more vulnerable to shocks, we regress the longitudinal standard deviation of $\log$ (consumption) of a household, constructed over all waves of data, on a dummy for whether the households is connected and isolated households. Doing so we find the coefficient on being connected is -.013 with a standard error of .004.
} 
a potential for resource transfers within family networks to finance schooling investments. These findings also neatly complement those of Rosenzweig and Wolpin [1993] and Fafchamps and Pender [1997] that both document in the context of India, how rural households are observed investing into cattle but not in higher return but non-collateralizable and lumpy investments in irrigation.

To probe further whether the impacts on human capital investments reflect relaxed credit constraints, Column 4 considers household responses in terms of child labor: the share of children aged 11-16 that households report as having worked in the week prior to the survey. This result matches with the earlier finding for schooling: (i) there is no reduction in child labor among eligible isolated households in response to resource inflows; (ii) eligible connected households significantly reduce the incidence of child labor by $3.6 \mathrm{pp}$ relative to counterfactual households in control villages. Taking the schooling and child labor results together suggests when connected households have more resources, they prefer to reallocate their children away from work (and thus choose to give up some income) and towards investing in their childrens' human capital. ${ }^{30}$

\subsection{Indirect Effects on Ineligibles}

Table 5 considers the sample of ineligibles $\left(D_{h}=I\right)$ and estimates ITEs from (3). These estimates measure the indirect effect of Progresa on ineligibles' investment, and are again identified exploiting only the random assignment of villages to treatment and control. Columns 1 and 2 show that for collateralizable investments into livestock: (i) neither ineligible isolated nor ineligible connected households have any significant change in the value of owned livestock relative to counterfactual households in control villages; (ii) this is the case for both small and large animal types of livestock. This lack of spillover effect to ineligibles suggest the large injection of resources that Progresa provides at the village level does not alter the marginal net benefit of making such livestock investments, and so these are independent of household, network or aggregate resources.

Repeating the analysis among ineligibles for schooling investment in Columns 3 and 4: (i) we continue to find no evidence of general equilibrium effects through the null response of isolated households; (ii) we also find muted investment responses among connected ineligibles. Hence if family networks share resources, they do so in a way that allows poorer network members, and hence eligible for Progresa, to increase non-collateralizable investments into human capital. Resource transfers that flow from eligibles to ineligibles within the network are largely spent on

\footnotetext{
${ }^{30}$ Of course, investments into livestock and human capital differ on other dimensions beyond those related to credit constraints. For example, if schooling is considered a more risky investment and isolated households are more risk averse than connected households, this might also be consistent with the documented pattern of responses. However, it would be inconsistent with the evidence in Table 1 that at baseline, isolated and connected households have similar levels of investment across all three types of activity.
} 
food consumption, as shown in Table 2. It is rational for schooling investments of poorer networks members to increase, rather than among less poor (ineligible) members: if the former do so, they increase the value of conditional cash transfers received, while this is not the case if ineligibles increase their schooling investment. ${ }^{31}$

Finally, Column 4 investigates the incidence of child labor among ineligibles: we find no significant difference in child labor between treatment and control villages of either isolated or connected households. This finding suggests the program does not have spillover effects through labor markets. The close to zero impact among connected and ineligible households $\left(\widehat{\beta}_{3}^{I}=-.009\right)$ suggests their children do not substitute for the reduction in child labor among eligible households in their family network documented earlier.

Considering together the ATE and ITE estimates on schooling are informative of changes in inequality in human capital investments within family networks in response to resource inflows. At baseline, eligible and ineligible connected households have similar levels of secondary school enrolment, 64\%. Hence the resource increase that eligibles experience allows them to overtake the investments made into human capital by less poor ineligibles in their family network. This is in contrast to the earlier result for consumption inequality within family networks, that was unchanged in response to significant resource injections into networks due to Progresa.

\subsection{Network Effects}

To complete the investment analysis, we estimate (6) focusing on the family network as the relevant unit. Table 6 presents the results for networks with at least one eligible household in them. On collateralizable investments, Column 1 reaffirms there is no significant increase in the value of small animal investments as a result of the network experiencing a positive injection of resources. Column 2 shows a similar pattern of null responses at the network level on the value of larger forms of livestock (recall the earlier positive ATE results on large animals in Table 4 were driven by isolated households who are not included in these NATE estimates).

Column 3 focuses on schooling investments and here we see relative to counterfactual networks in control villages: (i) for the average network member, secondary school enrolment rates increase by 6.0pp. In short, resource pooling arrangements among family networks can overcome credit

\footnotetext{
${ }^{31}$ Positive spillover effects on school enrolment of ineligibles have been documented in some other studies [Bobonis and Finan 2009, Lalive and Cattaneo 2009], although others have found no such spillovers [Schultz 2004, Behrman et al. 2005]. These differences might stem from alternative methodologies: Bobonis and Finan [2009] and Lalive and Cattaneo [2009] match children over waves and consider changes in individual enrolment status. Lalive and Cattaneo [2009] document program effects between October 1997 and November 1998, and consider enrolment for both primary school aged children and those transiting to secondary school. Bobonis and Finan [2009] document the spillovers to be larger among the poorest ineligibles. Our results indicate that on average, extended families do not strongly influence such spillovers in secondary enrolment.
} 
constraints into non-collateralizable investments only if the network as a whole experiences a sufficiently large resource increase. Column 4 considers the impact of resource inflows to child labor in family networks as a whole and shows the reduction in the incidence of child labor of $6.1 \mathrm{pp}$ is close to equal and opposite the magnitude of the increase in schooling (6.0pp).

Finally, Figure 3B exploits information on network architectures to see how the investment responses vary with the architecture of the family network. We see an intriguing pattern of responses to be considered in conjunction with the network responses for consumption shown in Figure 3A: (i) there are significant impacts on school enrolment for networks above and below the three statistics considered: the size of the network, its diameter, and its group closeness centrality; (ii) however in each case, within treatment villages, the response of those networks above the median is smaller than those below the median. Viewed alongside Figure 3A, this illustrates the interlinkage between consumption and investment choices for family networks subject to resource inflows. Larger and more dense networks that appear to have the greatest consumption response among their members are also those with marginally smaller investment responses.

\section{Consumption and Investment in the Longer Term}

We have documented how resource pooling in family networks allows for the relaxation of credit constraints for non-collateralizable investments such as those into the human capital. As the returns to such investments are realized, this has long term impacts on consumption for connected households relative to isolated households. To assess these longer term gains we exploit the final wave of household panel data collected in November 2003, five years after the first Progresa transfers were made in treated villages. From late 1999 onwards the experimental evaluation ended and the program was rolled out over all control villages. Hence when using this longer window of analysis into the post-evaluation period, it is useful to define a dummy $\Pi_{v}=1$ if village $v$ was originally randomly assigned to receive Progresa in 1998, and $\Pi_{v}=0$ otherwise. We then estimate the following specification for household $h$ in village $v$ :

$$
\Delta y_{h v}=\kappa_{0}+\kappa_{1} N_{h}+\kappa_{2} \Pi_{v}+\kappa_{3}\left(\Pi_{v} \times N_{h}\right)+\kappa^{\prime} \mathbf{X}_{h v 0}+\varepsilon_{h v},
$$

where $\Delta y_{h v}$ is the change in consumption/investment outcome from March 1998 and November 2003, $N_{h}$ is a dummy for whether household $h$ is connected or not, and $\mathbf{X}_{h v 0}$ includes the same set of characteristics as before. We continue to cluster standard errors by village. The coefficient of interest, $\kappa_{3}$, measures the difference-in-difference in outcomes between connected and isolated households (irrespective of their original eligibility status), from having been treated for the full 
five years relative to the short run effects documented earlier. Table 7 presents the results from tracking 14,000 households over this five year period.

On consumption, Column 1 shows that households embedded within family networks have monthly food expenditures that are 19.8pesos higher than for isolated households: recall that at baseline, there were no significant differences in food expenditures between connected and isolated households. This impact corresponds to a $14 \%$ increase in adult equivalent food expenditures over baseline levels. It is plausible that this reflects the returns to human capital investments being realized within the five-year window given secondary schooling lasts three years in this setting, and the perceived and actual returns to secondary schooling are substantial [Attanasio and Kaufmann 2014]. As Progresa transfers have the largest marginal impact in shifting children into secondary schooling then there could well be large productivity impacts because of the program, that feed into this magnitude of higher household resources in the longer term.

The remaining Columns examine if investment outcomes differ in the longer term between connected and isolated households. Columns 2 to 6 show no differential impact on livestock investments between isolated and connected households, for neither small nor large animals. This suggests: (i) the credit market for small livestock is well functioning; (ii) any gains to isolated households in being able to invest more into larger animals seem to be short lived: perhaps because such assets are liquidated when they later face a negative resource shock, as documented for rural Indian households by Rosenzweig and Wolpin [1993].

Column 6 examines non-collateralizable schooling investments: we see a significant differential impact between connected and isolated households: as Table 1 showed, at baseline these households had secondary school enrolment rates of $65 \%$ and $66 \%$ respectively. These longer term results show that this gap grows by $6.4 \mathrm{pp}$, corresponding to just under $10 \%$ of the baseline levels, five years after households and their network members begin experiencing exogenously timed resource inflows. Two points are of note. First, the result suggests that connected households do not reverse decisions to invest in their childrens' human capital over this five year time frame. Second, within-village inequality in investments in the human capital of secondary school-aged children increases because of resource pooling within family networks.

We note that these longer term differentials also vary with the intensity with which households experience positive resource shocks from Progresa. Consider the simple division of households between those above and below the median number of children aged 0-14 in the household at baseline: those households eligible with more children should receive greater valued transfers all else equal. In line with this we find the differential impact on food expenditures and secondary school investment of resource shocks between connected and isolated households with above the 
median number of children at baseline to be larger: the longer term impact on food consumption is 34 pesos (corresponding to a $24 \%$ increase over baseline levels), and the impact on schooling is 9.9pp (around $15 \%$ of the baseline level).

As in Gertler et al. [2012], we find that connected households do not converge back to preprogram poverty levels over this horizon. This suggests the interplay between resource inflows, and resource pooling to foster investment within family networks might enable them to escape the kinds of poverty trap that have long concerned development economists [Lewis 1954]. This is counter to the predictions of the literature highlighting kinship taxes as a key motive for within family resource transfers: such taxes lead to productive and allocative distortions, and thus can be a root cause of poverty traps.

\section{Conclusion}

This paper studies a novel motive for resource pooling in family networks in village economies: to relax credit constraints and facilitate investment, especially those in non-collateralizeable assets for which credit market imperfections are most binding. While there is an established literature examining risk-sharing motives for resource transfers within family networks, as well as motives based on obligations related to kinship taxes, our innovation is to examine the consequences of resource sharing on investment outcomes. We do so by exploiting the Progresa experimental evaluation data, in which extended family networks can be identified, households are subject to exogenous and large resource inflows, and detailed responses on consumption and an array of investments can be tracked in a panel of households over the long term. Our key findings show consumption and investment responses of households to resource inflows depend fundamentally on whether or not they are embedded in extended family networks. This has implications for consumption outcomes across all networks members, the nature of assets invested into, and the longer term trajectory out of poverty for the network as a whole.

Our contribution is empirical. However, our findings highlight there remains enormous scope for developing models of decision making within networks, that would properly micro-found the conceptual framework discussed. Key modelling aspects might be to: (i) jointly study consumption and investment decision; (ii) embed multiple motives for resource pooling into models (rather than studying risk insurance, kinship tax, and investment motives separately); (iii) consider how network architecture determines outcomes.

The role of policy when households engage in informal resource sharing arrangements has been much discussed. As Attanasio and Rios-Rull [2003] make precise in the context of risk-sharing 
motives for resource sharing, policies that partially counteract financial market imperfections can reduce welfare because if households only enter self-enforcing contracts, the amount of risk sharing that can be sustained in equilibrium depends on the harshness of the punishment and, therefore, the value of autarky. If policies increase the value of autarky relative to the value of being in the informal contract, risk sharing decreases, weakening the social fabric of village economies.

In our empirical context, if households view the increase in resources Progresa provides as being permanent, they have less reason to sustain resource pooling agreements with their extended family, all else equal, instead opting for autarky or to reformulate such arrangements among a smaller coalition of network members [Genicot and Ray 2003]. This does not happen: resource pooling is sustained among family networks when their poorest members experience resource inflows, and these gains in consumption and investment within the network persist over the long term (and even allow the poorest members of networks to overtake the richer members in terms of investments into their childrens' human capital). This suggests that within family networks, the degree of altruism for others is high, or mechanisms to punish or ostracize households that renege on their obligations are effective [Ambrus et al. 2014].

We close by highlighting two broader implications of our study. The first is the link between our results and the public finance literature on targeting: eligible and connected households share the transfers Progresa provides with less poor ineligibles. This leakage is substantial, with the marginal propensity to consume out of Progresa transfers being almost equal between eligible and ineligible households in the same family network. Combined with our results on consumption inequality in networks, we show that family networks partially undo transfer programs aimed at assisting the poor. Indeed, if all households were in a family network, transfer-based poverty programs would have little impact on inequality, if Pareto weights remained unchanged. This leakage towards ineligibles might be viewed negatively if it partially undoes the redistributive objectives of the policy maker, or could be viewed positively if households exploit private information to reach resource allocations maximizing social welfare. Understanding which of these scenarios is more accurate needs to be addressed in future work. ${ }^{32}$

Second, our longer term findings emphasize a virtuous cycle can be kick-started when a family network as a whole receives a sufficiently large injection of resources: we document how this allows poorer members of the network to invest in non-collateralizable assets, that then has feedback effects on longer term consumption as the returns to such investments are realized. This bridges to long-standing 'big push' theories of development, and an emerging set of evaluations highlighting

\footnotetext{
${ }^{32}$ Alatas et al. [2016] show that using private information of social networks in village economies leads to a different set of households being identified by communities as being the most needy, compared to other common targeting methods.
} 
that large-scale asset transfer programs can place households on trajectories out of poverty in the long term [Bandiera et al. 2016, Banerjee et al. 2016]. This all underlines the importance for future impact evaluations to trace and use of resource injections (be they in the form of assets, conditional cash transfers, or in some other metric), among family networks in village economies.

\section{References}

[1] Alatas.v, A.BAnerJee, A.Chandrasekhar, R.hanna And B.olken (2016) "Network Structure and the Aggregation of Information: Theory and Evidence from Indonesia," American Economic Review 106: 1663-704.

[2] Albarran.P And O.P.attanasio (2003) "Limited Commitment and Crowding Out of Private Transfers: Evidence from a Randomized Experiment," Economic Journal 113: C77-85.

[3] Ambrus.a, M.mobius And A.szeidl (2014) "Consumption Risk-Sharing in Social Networks," American Economic Review 104: 149-82.

[4] Angelucci.m And G.De Giorgi (2009) "Indirect Effects of an Aid Program: How Do Liquidity Injections Affect Ineligibles' Consumption?," American Economic Review 99: 486-508.

[5] Angelucci.m, G.De Giorgi, M.A.RAngel And i.RASUl (2010) "Family Networks and School Enrollment: Evidence from a Randomized Social Experiment," Journal of Public Economics 94: 197-221.

[6] Angelucci.m (2015) "Migration and Financial Constraints: Evidence from Mexico," Review of Economics and Statistics 97: 224-8.

[7] ATtanasio.o.P AND K.M.Kaufmann (2014) "Education Choices and Returns to Schooling: Mothers' and Youths' Subjective Expectations and Their Role by Gender," Journal of Development Economics 109: 203-16.

[8] ATtanasio.o.P And V.Lechene (2014) "Efficient Responses to Targeted Cash Transfers," Journal of Political Economy 122: 178-222.

[9] Attanasio.o.P, C.meghir and C.mommaerts (2015) Insurance in Extended Family Networks," NBER WP21059.

[10] Attanasio.o.P, C.meghir And A.santiago (2012) "Education Choices in Mexico: Using

a Structural Model and a Randomized Experiment to Evaluate PROGRESA," Review of Economic Studies 79: 37-66. 
[11] ATtanasio.O.P AND J-V.RIOS-RUlL (2003) "Consumption Smoothing and Extended Families," in M.Dewatripont, L.Hansen and S.Turnovsky (eds.), Advances in Economics and Econometrics: Theory and Applications, Eighth World Congress Econometric Society Monographs, Cambridge, England: Cambridge University Press.

[12] Baland.J-M, I.BOnjean, C.Guirkinger And R.ZIPARo (2015) The Economic Consequences of Mutual Help in Extended Families, mimeo, Namur.

[13] Baland.J-M, C.Guirkinger AND C.mali (2011) "Pretending to Be Poor: Borrowing to Escape Forced Solidarity in Cameroon," Economic Development and Cultural Change 60: $1-16$.

[14] BAndiera.o, R.BURGess, N.DAS, S.Gulesci, I.RAsul AND M.Sulaiman (2016) "Labor Markets and Poverty in Village Economies," Quarterly Journal of Economics, forthcoming.

[15] BANERJEe.A.V, A.CHANDRASEKhar, E.DUflo AND M.JACKSON (2014) Exposure to Formal Loans: Changes in Social Networks, mimeo, MIT.

[16] BanerJee.A.v, E.Duflo, R.Chattopadhyay And J.Shapiro (2016) The Long Term Impacts of a Graduation Program: Evidence from West Bengal, mimeo, MIT.

[17] Behrman.J.R, P.Sengupta And P.TOdd (2005) "Progressing Through PROGRESA: An Impact Assessment of a School Subsidy Experiment in Rural Mexico," Economic Development and Cultural Change 54: 237-76.

[18] Benjamin.D (1992) "Household Composition, Labor Markets, and Labor Demand: Testing for Separation in Agricultural Household Models," Econometrica 60: 287-322.

[19] Besley.T.J (1995) "Savings, Credit and Insurance," in H.Chenery and T.N.Srinivasan (ed.), Handbook of Development Economics Vol. 3, Elsevier.

[20] BHALla.S.S (1979) "Measurement Errors and the Permanent Income Hypothesis: Evidence from Rural India," American Economic Review 69: 295-307.

[21] Bianchi.m And BobBa.m (2013) "Liquidity, Risk, and Occupational Choices," Review of Economic Studies 80: 491-511.

[22] BINZEL.C, E.FIELD AND R.PANDE (2014) Does the Arrival of a Formal Financial Institution Alter Informal Sharing Arrangements? Evidence from India, mimeo, Harvard University. 
[23] Bobonis.G.J And F.finan (2009) "Neighborhood Peer Effects in Secondary School Enrollment Decisions," Review of Economics and Statistics 91: 695-716.

[24] Boltz-Lemmel.m (2013) How Can I Say No? Savings and Forced Solidarity in the Extended Family: Evidence from Senegal, mimeo, PSE.

[25] Chandrasekhar.a.G, C.Kinnan And H.LARreguy (2014) Social Networks as Contract Enforcement: Evidence from a Lab Experiment in the Field, mimeo, Stanford University.

[26] ChetTy.R And A.LOOney (2006) "Consumption Smoothing and the Welfare Consequences of Social Insurance in Developing Economies," Journal of Public Economics 90: 2351-6.

[27] Clark.G, N.Cummins, D.Diaz Vidal And y.hao (2014) The Son Also Rises: Surnames and the History of Social Mobility, Princeton: Princeton University Press.

[28] COATE.S AND M.RAVAllion (1993) "Reciprocity Without Commitment: Characterization and Performance of Informal Insurance Arrangements," Journal of Development Economics 40: 1-24.

[29] Cochrane.J.H (1991) "A Simple Test of Consumption Insurance," Journal of Political Economy 99: 957-76.

[30] COnley.t.G AND C.R.UdRY (2010) "Learning About a New Technology: Pineapple in Ghana," American Economic Review 100: 35-69.

[31] COX.D AND M.FAFChamps (2008) "Extended Family and Kinship Networks: Economic Insights and Evolutionary Directions," in T.P.Schultz and J.A.Strauss (ed.) Handbook of Development Economics Vol.4, Elsevier.

[32] Cunha.J, G.De giorgi and s.Jayachandran (2014) The Price Effects of Cash Versus InKind Transfers, mimeo, Northwestern University.

[33] De Janvry.e And E.SAdoulet (2006) "Making Conditional Transfer Programs More Efficient: Designing for Maximum Effect of the Conditionality," World Bank Economic Review 20: 1-29.

[34] Difalco.s And E.Bulte (2011) "A Dark Side of Social Capital?," Journal of Development Studies 47: 1128-51. 
[35] DI MARO.v (2004) Evaluation of the Impact of PROGRESA on Nutrition: Theory, Econometric Methods and an Approach to Deriving Individual Welfare Findings from Household Data, mimeo, UCL.

[36] eswaran.m And A.Kotwal (1986) "Access to Capital and Agrarian Production Organisation," Economic Journal 96: 482-98.

[37] FAfChamps.m And F.gubert (2007) "The Formation of Risk Sharing Networks," American Economic Review Papers and Proceedings 97: 75-9.

[38] FAfChAmps.m AND S.Lund (2003) "Risk-sharing Networks in Rural Philippines," Journal of Development Economics 71: 261-87.

[39] FAfChamps.m And J.Pender (1997) "Precautionary Saving, Credit Constraints, and Irreversible Investment: Theory and Evidence from Semi-Arid India," Journal of Business and Economic Statistics 15: 180-94.

[40] Foster.A.D And M.R.rosenzweig (2001) "Imperfect Commitment, Altruism, and the Family: Evidence from Transfer Behavior in Low-Income Rural Areas," Review of Economics and Statistics 83: 389-407.

[41] Genicot.G And D.RAy (2003) "Group Formation in Risk-Sharing Arrangements," Review of Economic Studies 70: 87-113.

[42] Gertler.P.J S.W.martinez And M.Rubio-Codina (2012) "Investing Cash Transfers to Raise Long-Term Living Standards," American Economic Journal: Applied Economics 4: 164-92.

[43] Guell.m, J.V.rodriguez mora And C.Telmer (2015) "The Informational Content of Surnames, the Evolution of Intergenerational Mobility and Assortative Mating," Review of Economic Studies 82: 693-735.

[44] JAKIElA.P AND O.OZIER (2016) Does Africa Need A Rotten Kid Theorem? Experimental Evidence from Village Economies, Review of Economic Studies 83: 231-68.

[45] Karaivanov.A And R.M.Townsend (2014) "Dynamic Financial Constraints: Distinguishing Mechanism Design From Exogenously Incomplete Regimes," Econometrica 82: 887-959.

[46] KINNAN.C (2014) Distinguishing Barriers to Insurance in Thai Villages, mimeo, Northwestern. 
[47] Kinnan.C And R.TOWnsend (2012) "Kinship and Financial Networks, Formal Financial Access, and Risk Reduction," American Economic Review Papers and Proceedings 102: 28993.

[48] LA FERRARA.E (2003) "Kin Groups and Reciprocity: A Model of Credit Transactions in Ghana," American Economic Review 93: 1730-51.

[49] Lalive.R And M.A.CATtaneo (2009) "Social Interactions in Schooling Decisions," Review of Economics and Statistics 91: 457-77.

[50] LEWIS.W.A (1954) "Economic Development with Unlimited Supplies of Labour," The Manchester School 22: 139-91.

[51] Ligon.e (1998) "Risk-Sharing and Information in Village Economies," Review of Economic Studies 65: 847-64.

[52] MACE.B.J (1991) "Full Insurance in the Presence of Aggregate Uncertainty," Journal of Political Economy 99: 928-56.

[53] MAZZOCCO.m AND S.SAIni (2012) "Testing Efficient Risk Sharing with Heterogeneous Risk Preferences: Semi-parametric Tests with an Application to Village Economies," American Economic Review 102: 428-68.

[54] MOFFitT.R.A (2001) "Policy Interventions, Low-Level Equilibria and Social Interactions," in S.N.Durlauf and H.Peyton Young (eds.) Social Dynamics, Cambridge, MA: MIT Press.

[55] MUNSHi.K (2011) "Strength in Numbers: Networks as a Solution to Occupational Traps," Review of Economic Studies 78: 1069-101.

[56] MUnshi.K And M.R.RosenzWeig (2016) "Networks and Misallocation: Insurance, Migration, and the Rural-Urban Wage Gap," American Economic Review 106: 46-98.

[57] Musgrove.P (1979) "Permanent Household Income and Consumption in Urban South America," American Economic Review 69: 355-68.

[58] Nurkse.R (1953) Problems of Capital Formation in Underdeveloped Countries, Oxford: Oxford University Press.

[59] PAXSON.C.H (1992) "Using Weather Variability to Estimate the Response of Savings to Transitory Income in Thailand," American Economic Review 82: 15-33. 
[60] Platteau.J-P (1997) "Mutual Insurance as an Elusive Concept in Traditional Rural Communities," Journal of Development Studies 33: 764-96.

[61] Platteau.J-P (2000) "Allocating and Enforcing Property Rights in Land: Informal versus Formal Mechanisms in Subsaharan Africa," Nordic Journal of Political Economy 26: 55-81.

[62] RosenzWeig.m.R (1988) "Risk, Implicit Contracts and the Family in Rural Areas of Lowincome Countries," Economic Journal 98: 1148-70.

[63] RosenzWeig.m.R And O.StARK (1989) "Consumption Smoothing, Migration, and Marriage: Evidence From Rural India," Journal of Political Economy 97: 905-26.

[64] ROSEnZWeig.m.R AND K.I.Wolpin (1993) "Credit Market Constraints, Consumption Smoothing, and the Accumulation of Durable Production Assets in Low-Income Countries: Investment in Bullocks in India," Journal of Political Economy 101: 223-44.

[65] Samphantharak.K And R.townsend (2010) Households as Corporate Firms: An Analysis of Household Finance Using Integrated Household Surveys and Corporate Financial Accounting, Econometric Society Monographs, Cambridge University Press.

[66] SCHUltz.P (2004) "School Subsidies for the Poor: Evaluating the Mexican Progresa Poverty Program," Journal of Development Economics 74: 199-250.

[67] Singh.I, L.SQUiRe And J.Strauss (1986) Agricultural Household Models: Extensions, Applications, and Policy, Baltimore:Johns Hopkins Press (for World Bank).

[68] SQuires.m (2016) Kinship Taxation as a Constraint to Microenterprise Growth: Experimental Evidence from Kenya, mimeo, LSE.

[69] TODD.P AND K.I.WOLPIN (2006) "Assessing the Impact of a School Subsidy Program in Mexico: Using a Social Experiment to Validate a Dynamic Behavioral Model of Child Schooling and Fertility", American Economic Review 96: 1384-417.

[70] TOWnSEnd.R (1994) "Risk and Insurance in Village India," Econometrica 62: 539-91.

[71] UDRY.C (1994) "Risk and Insurance in a Rural Credit Market: An Empirical Investigation in Northern Nigeria," Review of Economic Studies 61: 495-526. 
Table 1: Connected and Isolated Households at Baseline

Mean, standard deviation in parentheses and p-value on tests of equality in square brackets

$\begin{array}{llll}\text { (1) Connected } & \text { (2) Isolated } & \text { (3) Test of Equality }\end{array}$

\begin{tabular}{l} 
Households Households [Col 1. = Col. 2] \\
\hline
\end{tabular}

(4) Connected

(5) Isolated

[Treatment $=$ Control $] \quad[$ Treatment $=$ Control $]$

Panel A: Extended Family Networks

Percentage of Households

$79 \%$

$21 \%$

Panel B: Consumption

Monthly Food Expenditures [AE, pesos]

144

147

(120)

(126)

[.451]

[.401]

Panel C: Investment

Own Livestock [yes=1]

Total Livestock [pesos]

$\begin{array}{ll}.867 & .864 \\ (.340) & (.343)\end{array}$

(.340) $\quad(.343)$

$5505 \quad 5627$

(12687) (12982)

Small Livestock [pesos]

$1043 \quad 1077$

(3092) (3652)

Large Livestock [pesos]

12099

4729

(12262)

Primary School Enrolment Rate

.932

.908
$(1268)$

$(.232)$

(.268)

Secondary School Enrolment Rate

.648

(.405)

(.406)

[.728]

$[.757]$

[.558]

Panel D: Eligibility and Transfers

Eligible for Progresa [yes=1]

$\begin{array}{cc}.725 & .709 \\ (.446) & (.454) \\ 53.4 & 53.2 \\ (28.3) & (28.7) \\ 38.7 & \mathrm{n} / \mathrm{a}\end{array}$

Monthly Potential Transfers Eligible Households are Entitled to (November 1998, AE pesos)

Monthly Potential Transfers that an Average Household in an (16.7)

$$
\mathrm{n} / \mathrm{a}
$$

[.888]

Extended Family is Entitled to (November 1998, AE pesos)

$\mathrm{n} / \mathrm{a}$

[.422]

$\mathrm{n} / \mathrm{a}$

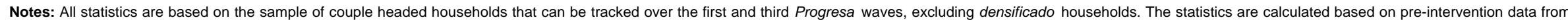

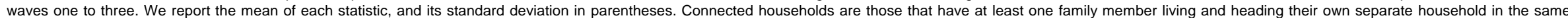

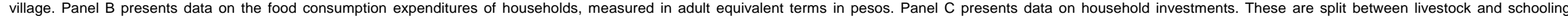

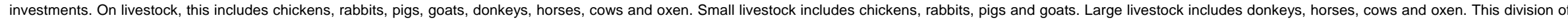

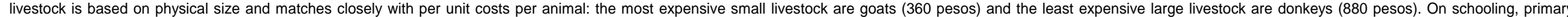

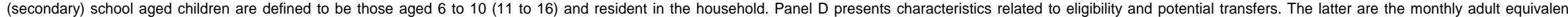

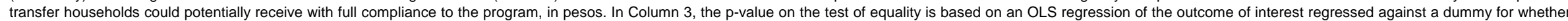

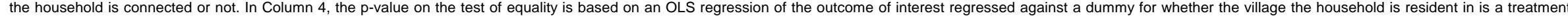

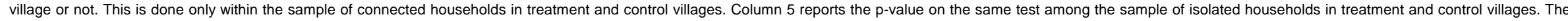

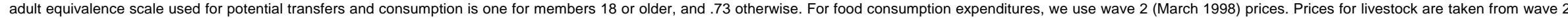
(March 1998) at the village level, replacing missing values with municipality averages. In March 1998, US\$1 = 10 pesos. We use the monthly Bank of Mexico CPI series to deflate monetary values for non-food items. 
Table 2: Treatment Effects on Monthly Food Consumption Expenditures

Sample in Column 1: Households Eligible for Progresa Transfers

Sample in Column 2: Households Ineligible for Progresa Transfers

Sample Period: Waves 2, 4, 5

Standard errors clustered by village

(1) Direct Treatment

(2) Indirect Treatment

Effect

Effect

\begin{tabular}{lc}
\hline ATE [lsolated] & 12.9 \\
ATE [Connected] & $(9.27)$ \\
\end{tabular}

ITE [lsolated]

ITE [Connected]

Notes: ${ }^{* \star *}$ denotes significance at $1 \%,{ }^{* \star}$ at $5 \%$, and ${ }^{*}$ at $10 \%$. The unit of observation is a household in survey wave t, and the sample in Column 1 (2) covers all eligible (ineligible) couple headed households in 503 villages. The number of households refers to the number observed in the first wave of data used, wave 2 (March 1998). The dependent variable is the adult equivalent monthly food expenditures (in pesos). The sample covers consumption data from waves 2 (March 1998), 4 (May 1999) and 5 (November 1999). OLS regression estimates are presented, where standard errors are clustered by village. Connected households are those that have at least one family member living and heading their own separate household in the same village. In all specifications we include the following controls (as measured at baseline): age of the household head, household size by age brackets (0-7, 8-14, 15-19, more than 19), the standardized household wealth index, village marginalization index, and region dummies. As the sample includes only eligible households and take-up is close to $100 \%$, the reported coefficients correspond to average treatment effects (ATE). In the lower half of the table, we report the implied marginal propensities to consume (MPC) out of actual Progresa transfers received by the household itself. Like the consumption measures, these actual transfers are also measured in adult equivalent monthly pesos. The adult equivalence scale used for potential transfers and consumption is one for members 18 or older, and .73 otherwise. For food consumption expenditures, we use wave 2 (March 1998) prices. In March 1998, US $\$ 1 \sim=10$ pesos. We use the monthly Bank of Mexico CPI series to deflate monetary values for non-food items. 


\title{
Table 3: Treatment Effects on Network Level Consumption
}

\author{
Sample: Networks With At Least One Eligible Household \\ Dependent Variable Consumption Measure: Monthly Food Expenditures \\ Sample Period: Waves 2, 4, 5 \\ Standard errors clustered by village
}

\section{(1) Mean Consumption}

(2) SD of Log

Consumption

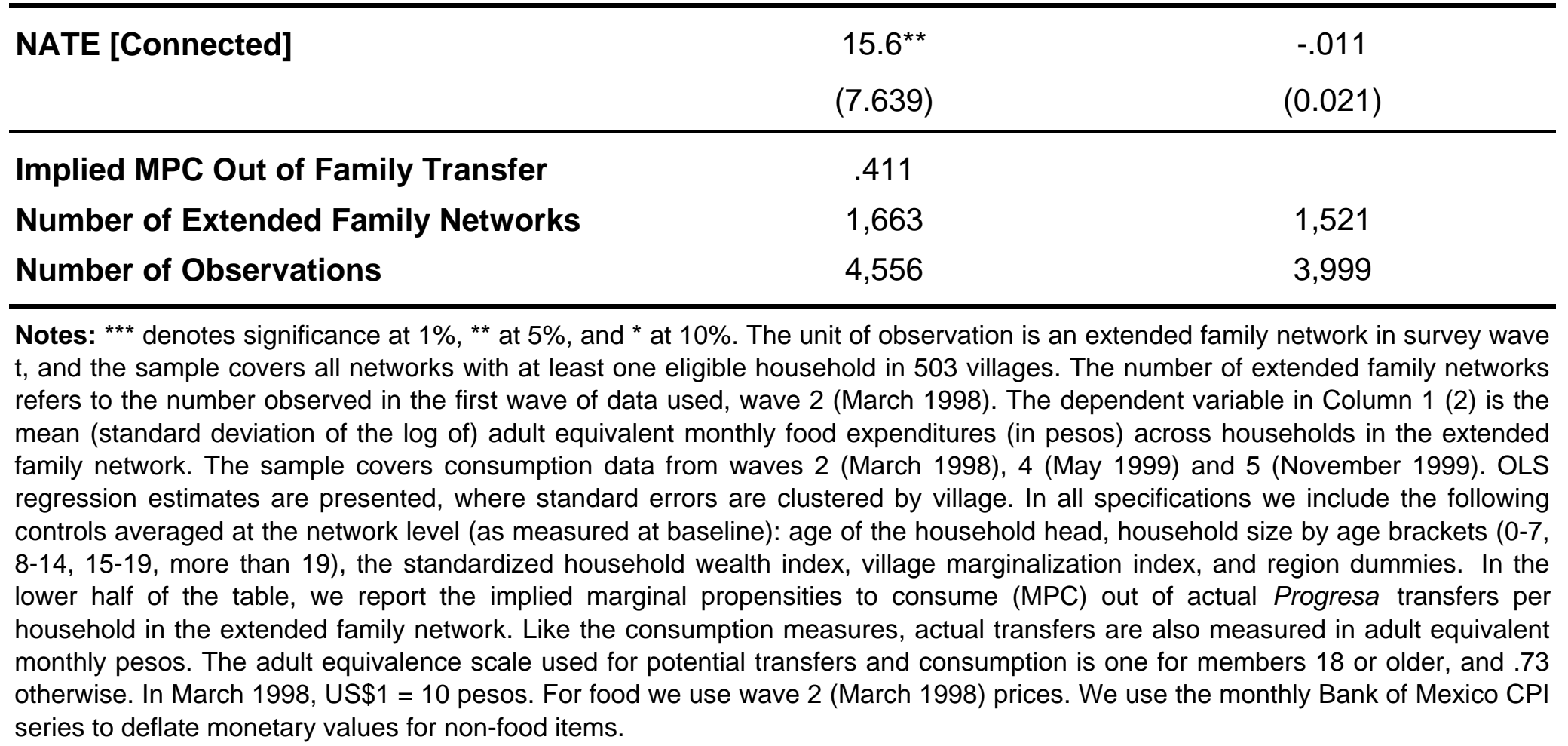




\section{Table 4: Direct Treatment Effects on Investment}

\section{Sample: Households Eligible for Progresa Transfers \\ Sample Period: Waves 2, 4, 5 \\ Standard errors clustered by village \\ Livestock Ownership (Value)}

(1) Small Animals

(2) Large Animals

\begin{tabular}{lcccc}
\hline ATE [Isolated] & 23.3 & $887^{*}$ & -.013 & $(.026)$ \\
& $(76.9)$ & $(487)$ & $.075^{* * *}$ & $(.026)$ \\
ATE [Connected] & 77.0 & 110 & $(.015)$ & $-.036^{* *}$ \\
\hline Number of Households & $(60.0)$ & $(330)$ & 4,659 & $(.015)$ \\
Number of Observations & 9,989 & 7,206 & 14,782 \\
\hline
\end{tabular}

Notes: ${ }^{* * *}$ denotes significance at $1 \%,{ }^{* *}$ at $5 \%$, and ${ }^{*}$ at $10 \%$. The unit of observation is a household in survey wave $t$, and the sample covers all eligible couple headed households in 503 villages. The number of households refers to the number observed in the first wave of data used, wave 2 (March 1998). In Column 1, 'small' livestock includes chickens, rabbits, pigs and goats. In Column 2, 'large' livestock includes donkeys, horses, cows and oxen. This division of livestock is based on physical size. Prices for livestock are taken from wave 2 (March 1998) at the village level, replacing missing values with municipality averages. The dependent variable in Column 3 is the share of children aged 11-16 that are resident and enrolled in secondary schooling. The dependent variable in Column 4 is the share of children aged 11 to 16 that households report as having worked in the week prior to the survey. The sample covers investment/child labor data from waves 2 (March 1998), 4 (May 1999) and 5 (November 1999). OLS regression estimates are presented, where standard errors are clustered by village. Connected households are those that have at least one family member living and heading their own separate household in the same village. In all specifications we include the following controls (as measured at baseline): age of the household head, bins for household size by age brackets (0-7, 8-14, 15-19, more than 19), the standardized household wealth index, the village marginalization index, and region dummies. In Columns 3 and 4 we also control for the household's primary school enrolment rate at baseline. As the sample includes only eligible households and take-up is close to $100 \%$, the reported coefficients correspond to average treatment effects (ATE). 
Table 5: Indirect Treatment Effects on Investment

Sample: Households Ineligible for Progresa Transfers

Sample Period: Waves 2, 4, 5

Standard errors clustered by village

Livestock Ownership (Value)

(1) Small Animals

(2) Large Animals

(3) Secondary School Enrolment

Human Capital Enrolment

(4) Child Labor

\begin{tabular}{lcccc}
\hline ITE [Isolated] & 3.63 & -443 & -.047 & .044 \\
& $(391)$ & $(1257)$ & $(.054)$ & $(.048)$ \\
ITE [Connected] & -72.5 & -43.3 & -.015 & -.009 \\
& $(222)$ & $(902)$ & $(.032)$ & $(.024)$ \\
\hline Number of Households & 3,772 & 2,575 & 863 \\
Number of Observations & 10,482 & 7,105 & 2,637 & 863 \\
\hline
\end{tabular}

Notes: ${ }^{* \star *}$ denotes significance at $1 \%,{ }^{* *}$ at $5 \%$, and ${ }^{*}$ at $10 \%$. The unit of observation is a household in survey wave $t$, and the sample covers all ineligible couple headed households in 503 villages. The number of households refers to the number observed in the first wave of data used, wave 2 (March 1998). In Column 1, 'small' livestock includes chickens, rabbits, pigs and goats. In Column 2, 'large' livestock includes donkeys, horses, cows and oxen. This division of livestock is based on physical size. Prices for livestock are taken from wave 2 (March 1998) at the village level, replacing missing values with municipality averages. The dependent variable in Column 3 is the share of children aged 11-16 that are resident and enrolled in secondary schooling. The dependent variable in Column 4 is the share of children aged 11 to 16 that households report as having worked in the week prior to the survey. The sample covers investment/child labor data from waves 2 (March 1998), 4 (May 1999) and 5 (November 1999). OLS regression estimates are presented, where standard errors are clustered by village. Connected households are those that have at least one family member living and heading their own separate household in the same village. In all specifications we include the following controls (as measured at baseline): age of the household head, bins for household size by age brackets (0-7, 8-14, 15-19, more than 19), the standardized household wealth index, the village marginalization index, and region dummies. In Columns 3 and 4 we also control for the household's primary school enrolment rate at baseline. As the sample includes only ineligible households, the reported coefficients correspond to indirect treatment effects (ITE). 
Table 6: Treatment Effects on Network Level Investment

Sample: Networks With At Least One Eligible Household

Sample Period: Waves 2, 4, 5

Standard errors clustered by village

Livestock Ownership (Value)

(1) Small Animals

(2) Large Animals

\begin{tabular}{llc}
\hline NATE [Connected] & 226 & 528 \\
& $(163)$ & $(476)$ \\
\hline Number of Extended Family Networks & 1598 & 1072 \\
Number of Observations & 4382 & 2,965 \\
\hline
\end{tabular}

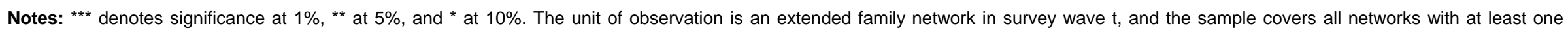

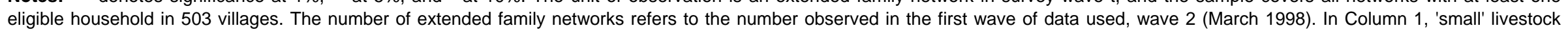

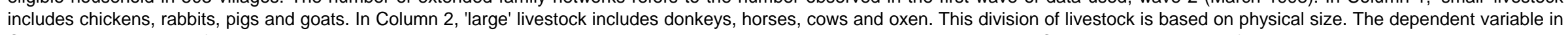

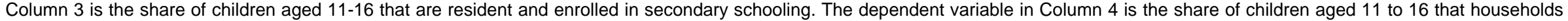

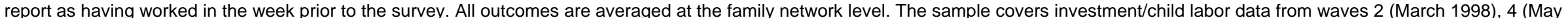

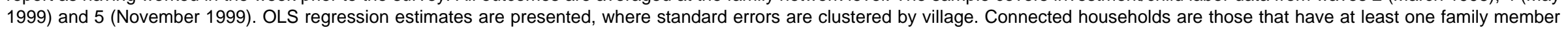

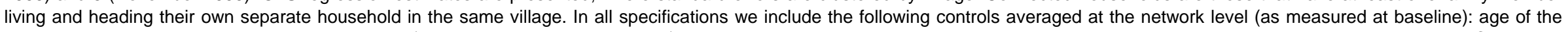

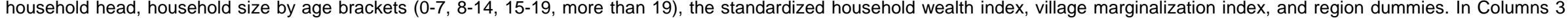
and 4 we also control for the household's primary school enrolment rate at baseline. Enrolment

(4) Child Labor

\begin{tabular}{cc}
$.060^{\star * *}$ & $\begin{array}{c}.061^{* \star *} \\
(.019)\end{array}$ \\
\hline 1442 & $(.019)$ \\
3,683 & 1431 \\
3,669
\end{tabular}

(3) Secondary School 
Table 7: Consumption and Investment in the Longer Term

\section{Sample: All Couple Headed Households}

Sample Period: Waves 2, 8

Standard errors clustered by village

\begin{tabular}{|c|c|c|c|c|c|c|}
\hline & $\begin{array}{l}\text { (1) Monthly } \\
\text { Food } \\
\text { Expenditures }\end{array}$ & $\begin{array}{c}\text { (2) Ownership } \\
\text { of Small } \\
\text { Livestock }\end{array}$ & $\begin{array}{c}\text { (3) Value of } \\
\text { Small Livestock } \\
\text { Owned }\end{array}$ & $\begin{array}{l}\text { (4) Ownership } \\
\text { of Large } \\
\text { Livestock }\end{array}$ & $\begin{array}{l}\text { (5) Value of Large } \\
\text { Livestock Owned }\end{array}$ & $\begin{array}{c}\text { (6) Secondary } \\
\text { School Enrolment }\end{array}$ \\
\hline Longer Term Differential [Connected - Isolated] & $\begin{array}{l}19.8^{* *} \\
(8.31)\end{array}$ & $\begin{array}{l}-.003 \\
(.027)\end{array}$ & $\begin{array}{l}-27.3 \\
(111)\end{array}$ & $\begin{array}{l}.031 \\
(.024)\end{array}$ & $\begin{array}{l}-13.8 \\
(599)\end{array}$ & $\begin{array}{l}.064^{* *} \\
(.031)\end{array}$ \\
\hline Number of Households & 14,440 & 14,437 & 13,761 & 14,440 & 9,781 & 7,719 \\
\hline Number of Observations & 26,472 & 26,402 & 25,611 & 26,410 & 19,824 & 15,639 \\
\hline
\end{tabular}


Table A1: Key Variable Definitions and Data Availability by Wave of Progresa Evaluation Data

\begin{tabular}{|c|c|c|c|c|c|c|c|c|c|}
\hline \multirow[b]{2}{*}{ Variable } & \multirow[b]{2}{*}{ Description } & \multicolumn{5}{|c|}{ Experimental Waves } & \multicolumn{3}{|c|}{ Non-Experimental Waves } \\
\hline & & $\begin{array}{l}\text { Wave } 1 \\
\text { Oct } 1997\end{array}$ & $\begin{array}{l}\text { Wave } 2 \\
\text { Mar } 1998\end{array}$ & $\begin{array}{l}\text { Wave } 3 \\
\text { Nov } 1998\end{array}$ & $\begin{array}{c}\text { Wave } 4 \\
\text { May } 1999\end{array}$ & $\begin{array}{l}\text { Wave } 5 \\
\text { Nov } 1999\end{array}$ & $\begin{array}{c}\text { Wave } 6 \\
\text { May } 2000\end{array}$ & $\begin{array}{l}\text { Wave } 7 \\
\text { Nov } 2000\end{array}$ & $\begin{array}{l}\text { Wave } 8 \\
\text { Nov } 2003\end{array}$ \\
\hline \multicolumn{10}{|l|}{ Panel A: Progresa Transfers } \\
\hline Actual PROGRESA transfer & From administrative records & No & No & $\mathbf{x}$ & $\mathbf{x}$ & $\mathbf{x}$ & No & No & No \\
\hline \multicolumn{10}{|l|}{ Panel B: Consumption } \\
\hline Monthly Food Expenditures & From seven days recall consumption of 36 items & No & Yes & $\mathrm{x}$ & Yes & Yes & $\mathrm{x}$ & $\mathrm{x}$ & $\mathrm{x}$ \\
\hline \multicolumn{10}{|l|}{ Panel C: Investment } \\
\hline Livestock & $\begin{array}{l}\text { Ownership (and value) of poultry, rabbits, goats, pigs, } \\
\text { horses, donkeys, oxen and cows }\end{array}$ & $\mathrm{x}$ & Yes & $\mathbf{x}$ & Yes & Yes & $\mathbf{x}$ & No & Yes \\
\hline Primary School Enrolment Rate & $\begin{array}{l}\text { Share of } 6-11 \text { year olds in the household that are } \\
\text { enrolled in primary school }\end{array}$ & $\mathrm{x}$ & Yes & $\mathbf{x}$ & Yes & Yes & $\mathbf{x}$ & $\mathbf{x}$ & Yes \\
\hline Secondary School Enrolment Rate & $\begin{array}{l}\text { Share of } 11-16 \text { year olds in the household that are } \\
\text { enrolled in secondary school }\end{array}$ & $\mathrm{x}$ & Yes & $\mathbf{x}$ & Yes & Yes & $\mathbf{x}$ & $\mathbf{x}$ & Yes \\
\hline
\end{tabular}

Notes: No = data unavailable; Yes = data available and used for the analysis; $\mathrm{X}=$ data available but not used for the analysis. The Columns refer to each data wave, where the first five waves from October 1997 to November 1999 cover the experimental part of the evaluation in which villages were assigned to treatment or control status. From Wave 6 onwards, control villages are also treated (and so these data waves are not used in any of the analysis that exploits the random assignment of villages to treatment). Depending on the village, the Progresa program starts just prior to, and around the time of, Wave 3 , and so we exclude observations from Wave 3 from our main analysis. Panel A reports on data availability in relation to Progresa transfers data. Actual data on transfers received by households are obtained from administrative records. Data on the potential transfer that a household could be entitled to is constructed based on the age and gender composition of the household in Wave 3. Panel B reports on data availability in relation to household consumption. In Waves 1-5, the household food consumption measure is constructed from 36 food items: households report the quantity consumed the week prior to interview, as well as the quantity purchased and its cost. If expenditure on an item is missing, but the amount purchased is recorded, we impute the median price reported in the village (if at least 30 households can be used to compute the price). Otherwise, we use the same method but impute the median price at the municipality or state level. Once we have household-specific prices for each food item, we multiply them by each quantity consumed (we do this rather than considering reported food expenditures as that underestimates the value of consumed if some items are consumed out of home production). To avoid incorporating endogenous price responses into the food consumption measure, we use prices from wave 3 (November 1998) to impute prices in later waves (when Progresa program is running). In Waves 6 onwards, the food consumption measure is based on seven aggregate food categories (frutas y verduras; maíz; frijol; arroz; 5 . pollo, carne de res; huevo; leche, queso). To compute adult equivalents for food consumption, we use the equivalence scale estimated by Di Maro [2004] using the same Progresa data. According to this, the adult equivalence scale on is one for members 18 or older, and 73 otherwise. We use the monthly Bank of Mexico CPI series to deflate monetary values. Panel C reports on data availability in relation to household investment Small livestock includes chickens, rabbits, pigs and goats. Large livestock includes donkeys, horses, cows and oxen. This division of livestock is based on physical size and matches closely with per unit costs per animal: the most expen with municipality averages. On schooling, primary (secondary) school aged children are defined to be those aged 6 to 10 (11 to 16) and resident in the household. 


\section{Figure 1: Family Tree}

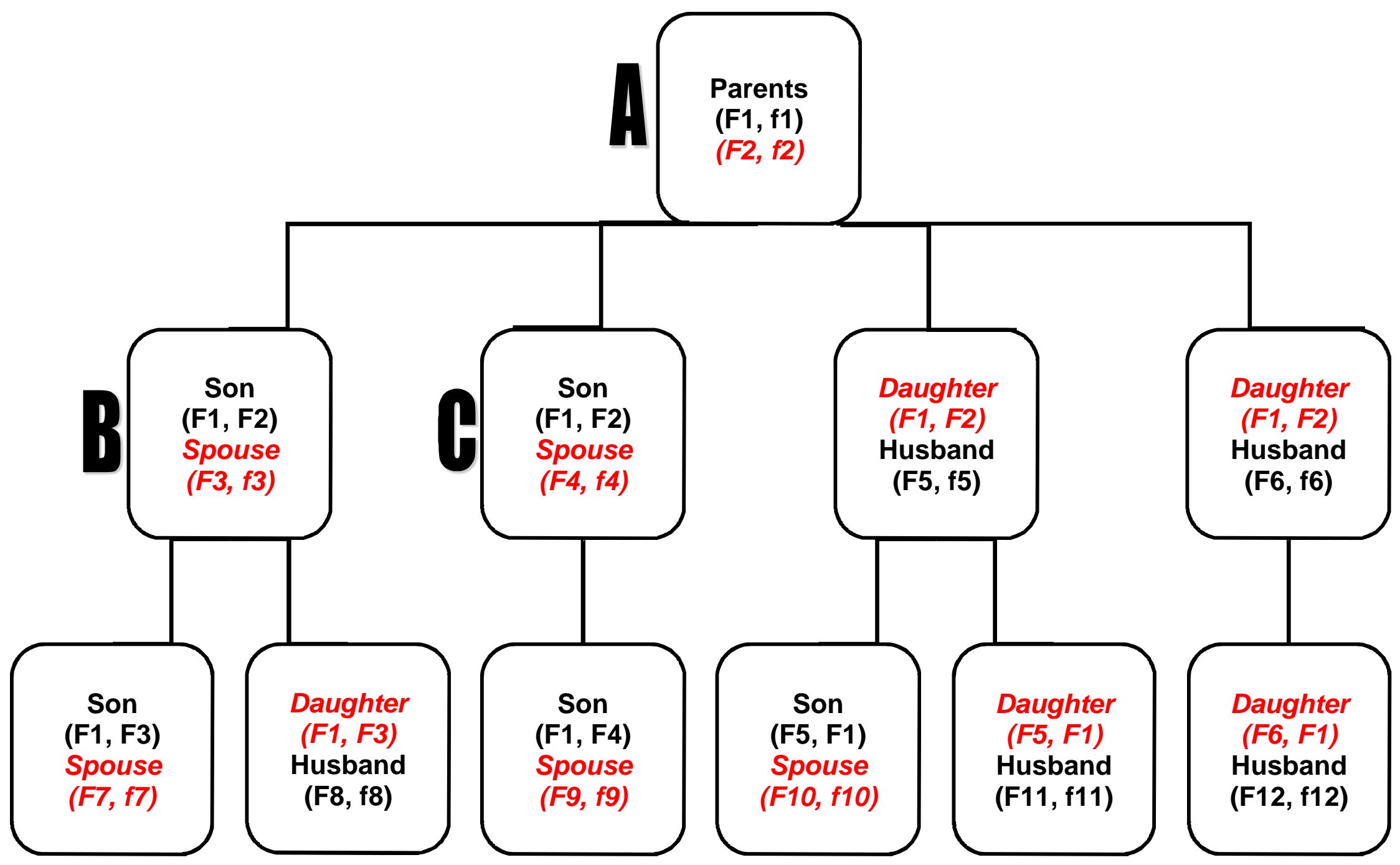

Notes: We use the convention that the head's surnames are written in standard (black) font, and those of his wife are written in (red) italics. Paternal surnames are indicated in upper case (F1, F2) and maternal surnames are indicated in lower case $(f 1, f 2)$. First names are not shown as they are not relevant for the construction of extended family ties. Each household in the family tree is assumed to be couple headed purely to ease the exposition. 


\section{Figure 2A: Distribution of Daily Per Capita Consumption Expenditures All Households}

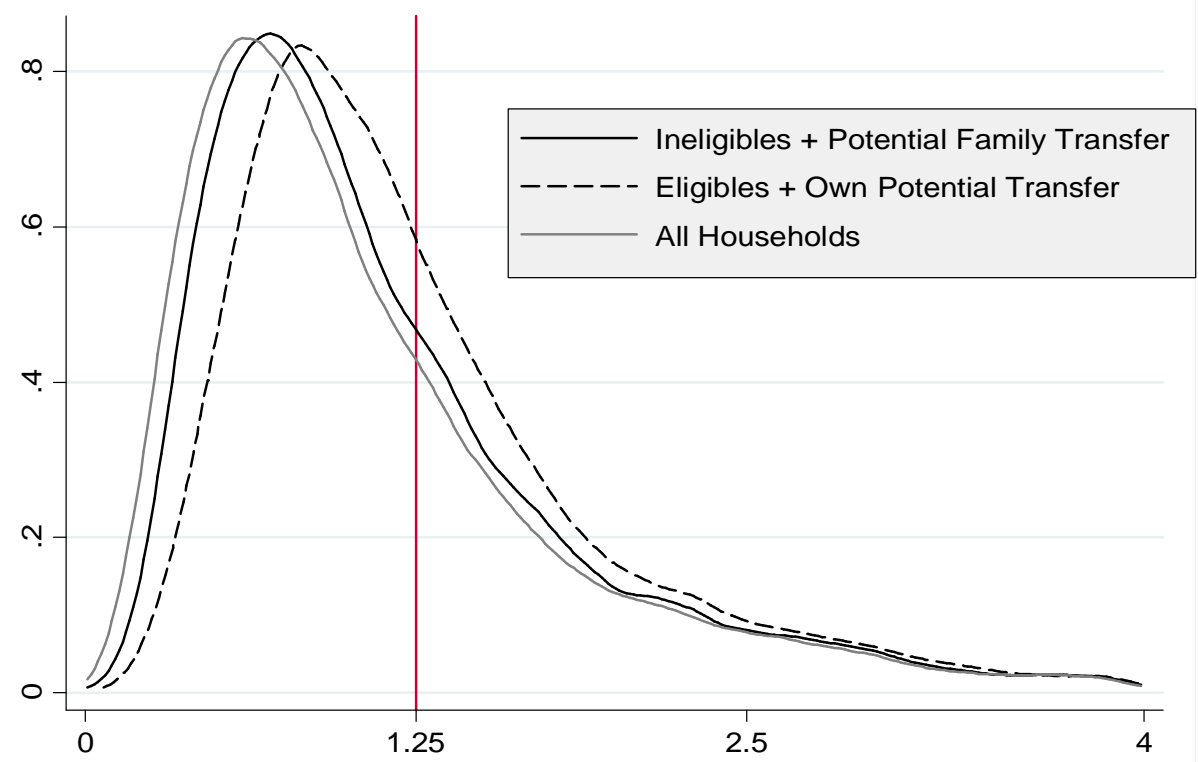

Daily Per Capita Consumption Expenditure in March 1998, Measured in 2003 US Dollars

\section{Figure 2B: ATE and ITE Impacts on the Distribution of Daily Per Capita Consumption Expenditures Connected Households}

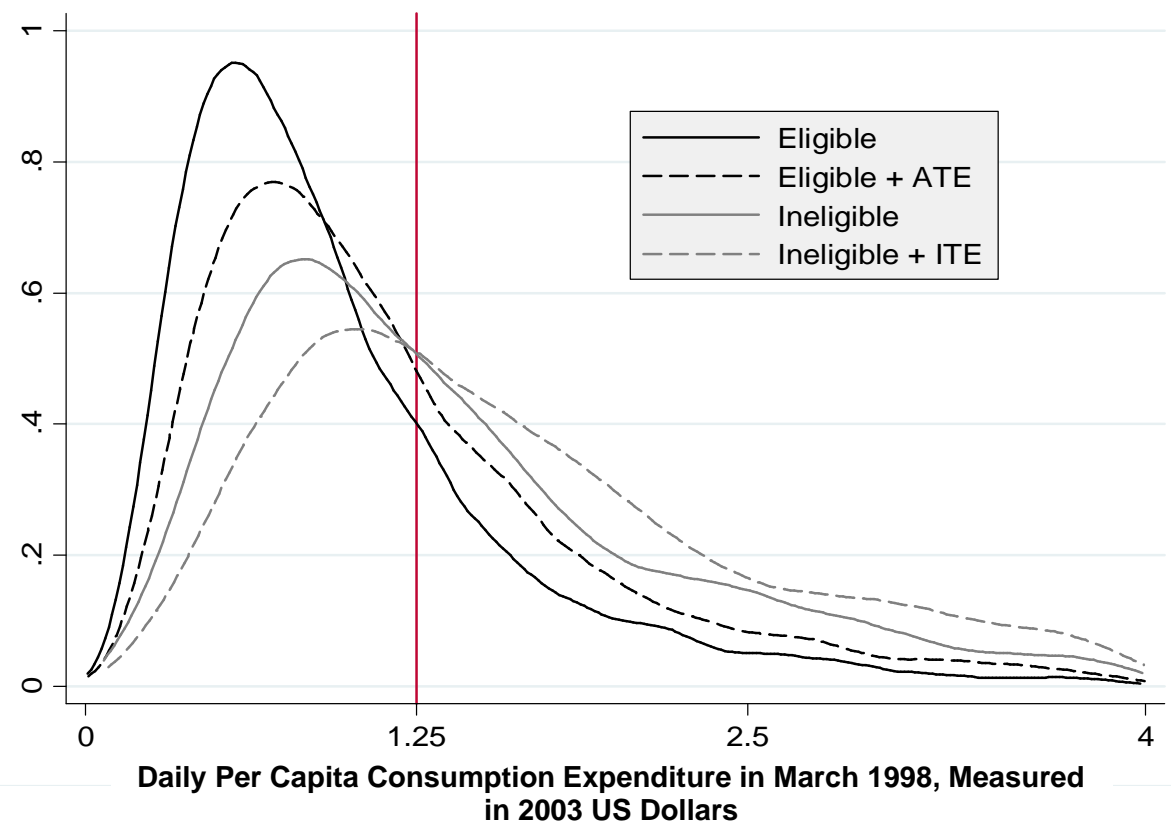

Notes: Figures $2 \mathrm{~A}$ and $2 \mathrm{~B}$ show the distribution of per capita household consumption (food and non-food combined) in 1997, as measured at 2003 US dollars. Values are trimmed at $\$ 4$. The vertical red line therefore corresponds to the global poverty line of $\$ 1.25$ /day. In Figure $2 \mathrm{~A}$, all couple headed households (eligible and ineligible) are included. The additional distributions then include the per capita resources potentially available to eligible households from Progresa, and those potentially available to ineligible households through resource transfers originating from eligible members of their extended family network. In Figure 2B, all couple headed connected households (eligible and ineligible) are used. The figure shows the distributional impact on eligible households of the ATE of their own positive resource shock, and the distributional impact on ineligible impacts of the ITE of their family members receiving resources, and redistributing them within the family network. 


\section{Network Responses and Network Architecture Figure 3A: NATE Estimates on Food Consumption Expenditures}

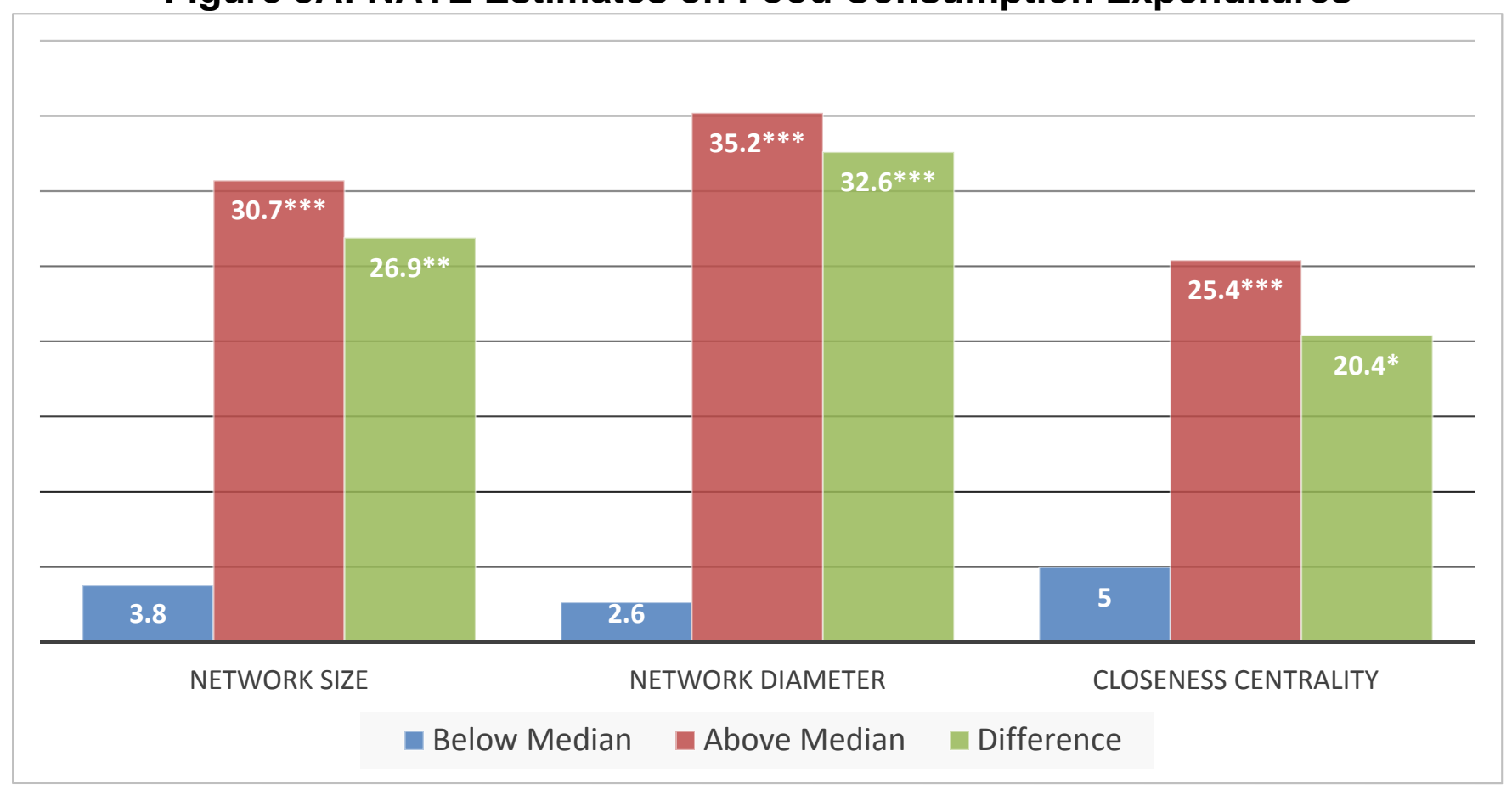

\section{Figure 3B: NATE Estimates on Secondary School Enrolment Rate}

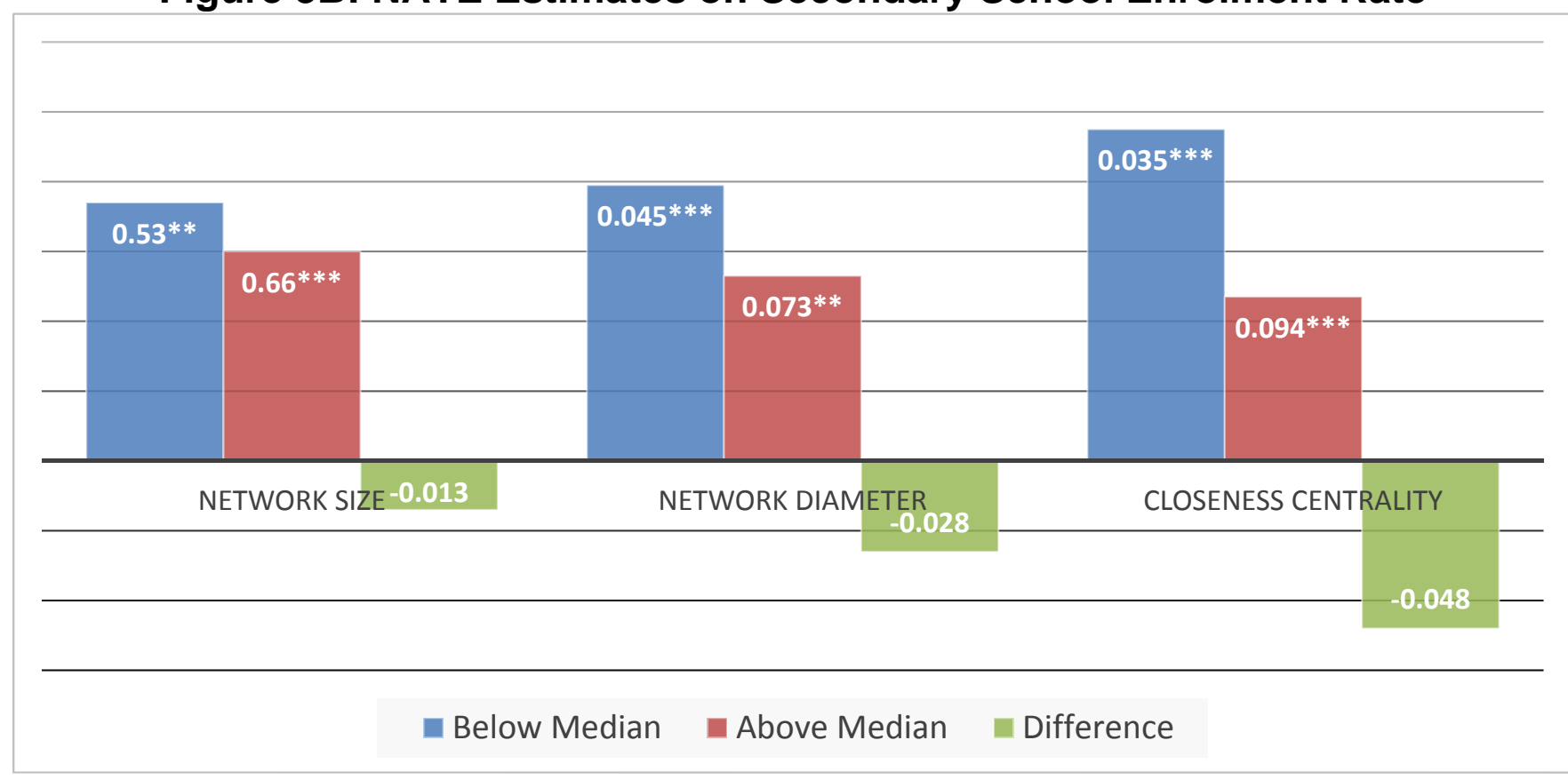

Notes: The figures show heterogeneous NATE estimates across networks with above/below the median of a given characteristic: Figure $3 \mathrm{~A}$ shows these effects where food consumption expenditures, and Figure 3B shows them for secondary school enrolment rates. The three network characteristics considered are: (i) the network size (namely, the total number of households in the family network); (ii) the diameter of the network (namely, the maximum distance from one household to another in the network); (iii) the closeness of the network as measured by group closeness centrality index. For each characteristics we show the NATE impacts above and below the median of each statistic (as calculated over all family networks with at least one eligible household in them), as well as the difference between the two NATE estimates. On each bar, ${ }^{* * *}$ denotes significance at $1 \%,{ }^{* *}$ at $5 \%$, and ${ }^{*}$ at $10 \%$. 